\title{
An effective stress analysis for predicting the evolution of SCR-seabed stiffness accounting for consolidation
}

\author{
ZEFENG ZHOU*, CONLETH D. O’LOUGHLIN† and DAVID J. WHITE
}

\begin{abstract}
Steel catenary risers (SCRs) are an efficient solution to transfer hydrocarbons from deep-water seabeds to floating facilities. SCR design requires an assessment of the fatigue life in the touchdown zone, where the riser interacts with the seabed, which relies on reliable estimates of the SCR-seabed stiffness over the design life. Current models for SCR-seabed stiffness consider only undrained conditions, neglecting the development and dissipation of excess pore pressures that occur over the life of the SCR. This consolidation process alters the seabed strength and consequently the SCR-seabed stiffness. This paper summarises experimental data that show that long-term cyclic vertical motion of an SCR at the touchdown zone leads to a reduction in seabed strength due to remoulding and water entrainment, but that this degradation is eclipsed by the regain in soil strength during consolidation. The main focus of this paper is on prediction of the temporal changes in seabed strength and stiffness due to long-term cyclic shearing and consolidation, to support calculations of SCR-seabed interaction. The predictions are obtained using a framework that considers the change in effective stress and hence soil strength using critical state concepts, and that considers the soil domain as a one-dimensional column of elements. The merit of the model is assessed by way of simulations of SCR centrifuge model tests with over 3000 cycles of repeated undrained vertical cycles in normally consolidated kaolin clay. Comparisons of the simulated and measured profiles of SCR penetration resistance reveal that the model can capture accurately the observed changes in SCR-seabed stiffness. Example simulations show the merit of the model as a tool to assess the timescale in field conditions over which this order of magnitude change in seabed stiffness occurs. It is concluded that current design practice may underestimate the seabed stiffness significantly, but the new approach allows rapid checking of this for particular combinations of SCR and soil conditions.
\end{abstract}

KEYWORDS: consolidation; offshore engineering; pipes \& pipelines; soil/structure interaction

\section{INTRODUCTION}

Steel catenary risers (SCRs) are an efficient option in deep water for oil and gas transmission from the seabed to a floating structure (see Fig. 1(a)). SCRs undergo long-term cyclic motion due to operational loads from the floating structure and environmental loads from waves and currents. For an element of SCR at the touchdown zone (TDZ), the cyclic shearing of the surrounding soil results in progressive generation of positive excess pore pressure in clays. This excess pore pressure causes degradation of the soil strength, and also reductions in stiffness. After reconsolidation periods, dissipation of this excess pore pressure leads to increases in soil strength and stiffness (Hodder et al., 2009; Yuan et al., 2017; Hou et al., 2018).

Assessing the fatigue life of an SCR is one of the most challenging issues in design practice. Fatigue life calculations are strongly influenced by the seabed strength and stiffness at the TDZ (Kimiaei et al., 2010; Li \& Low, 2012; Elosta et al., 2013, 2014; Queau et al., 2013). Therefore, an accurate

Manuscript received 19 November 2018; revised manuscript accepted 11 April 2019. Published online ahead of print 6 June 2019. Discussion on this paper closes on 1 September 2020, for further details see p. ii.

$*$ Centre for Offshore Foundation Systems and ARC Research Hub for Offshore Floating Facilities, University of Western Australia, Perth, WA, Australia (Orcid:0000-0002-3575-8810).

$\uparrow$ Centre for Offshore Foundation Systems and ARC Research Hub for Offshore Floating Facilities, University of Western Australia, Perth, WA, Australia.

$\$$ University of Southampton, Southampton, UK. prediction of seabed strength and stiffness is necessary for a reliable assessment of fatigue life.

The majority of the current prediction methods (see summary in Table 1) consider only undrained soil behaviour using a total stress approach, and can include different loaddisplacement paths at either penetration, uplift, loss of contact, or re-penetration (see Fig. 1(b)). The various models differ in how they formulate the hysteretic loaddisplacement behaviour for the different modes, simplified as either a 'closed hysteresis loop' (e.g. Aubeny \& Biscontin, 2009; Voie et al., 2014), or by adopting an 'open hysteresis loop' during SCR penetration and extraction (e.g. You et al., 2008; Randolph \& Quiggin, 2009; Zargar, 2017). In general, the models account for soil strength degradation due to the cyclic motion of the SCR through the formulation adopted for the load-displacement response; for example, by predicting a progressive increase in embedment from cycles of compressive load. However, they do not explicitly link soil strength to the change in effective stress associated with excess pore pressure generation due to undrained shearing.

Recent experimental studies (Hodder et al., 2009; Yuan et al., 2017; Hou et al., 2018) showed that the continued vertical cyclic motion of an SCR at the TDZ in soft clay results in progressive generation of excess pore pressure and degradation of soil strength, with a reduction in stiffness. However, over time dissipation of this excess pore pressure leads to a reduction in specific volume and a regain of soil strength and stiffness. The implication for SCR design is that the choice of soil stiffness in the fatigue analysis should be higher than that associated with full degradation of the soil strength. Although absolute magnitudes will be controlled by the timescales of interest and the rate at which consolidation 

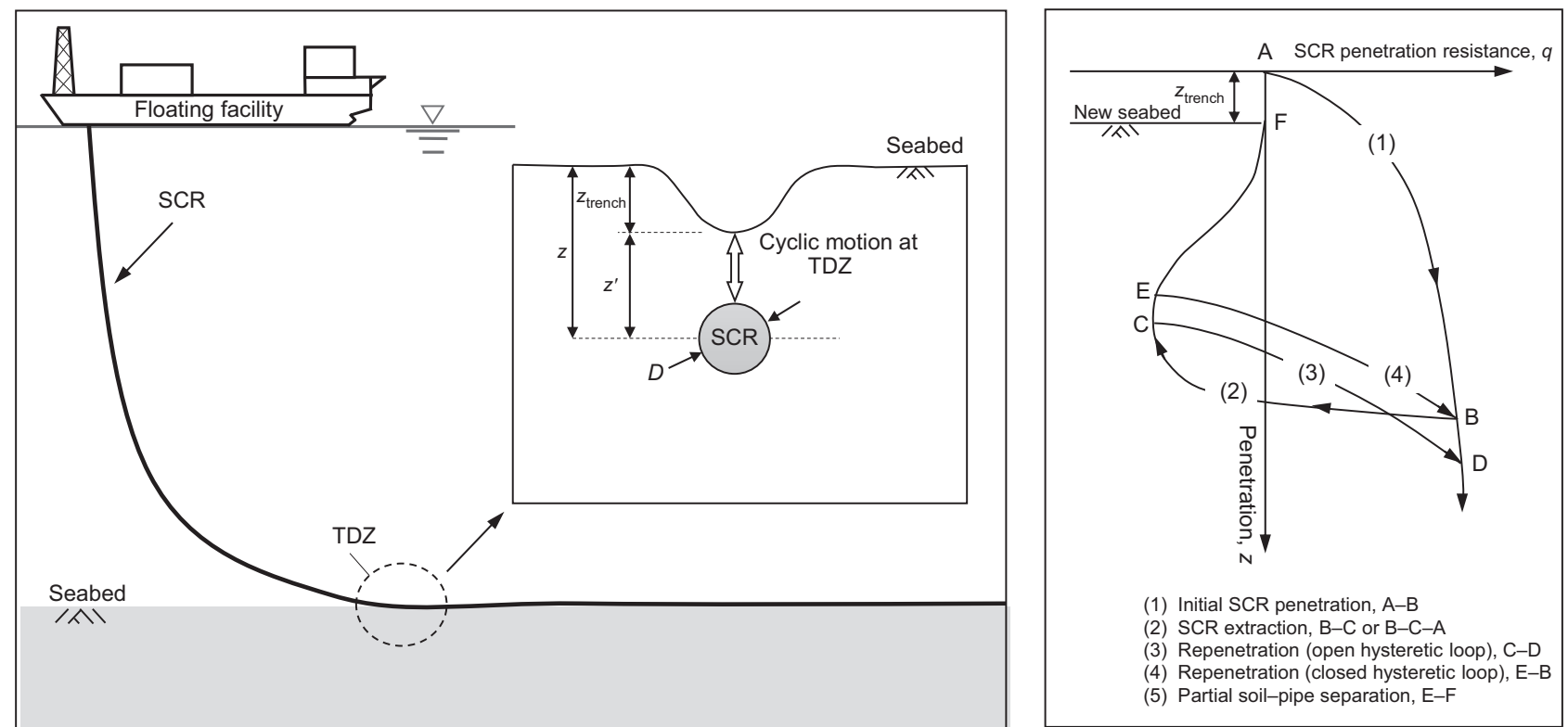

Fig. 1. Steel catenary risers: (a) problem definition and notation; (b) typical soil response during vertical cyclic motion (after Aubeny \& Biscontin, 2009)

Table 1. SCR-seabed interaction models

\begin{tabular}{|c|c|c|c|c|c|c|c|c|}
\hline \multirow{3}{*}{$\begin{array}{l}\text { SCR-seabed } \\
\text { interaction analysis }\end{array}$} & \multirow{2}{*}{\multicolumn{2}{|c|}{$\begin{array}{l}\text { Seabed hysteretic } \\
\text { load-displacement } \\
\text { modes }\end{array}$}} & \multirow{3}{*}{$\begin{array}{l}\text { Effect } \\
\text { of water } \\
\text { entrainment }\end{array}$} & \multirow{3}{*}{$\begin{array}{l}\text { Stress } \\
\text { domain }\end{array}$} & \multicolumn{2}{|c|}{ Cyclic loading effect } & \multicolumn{2}{|c|}{ Consolidation effect } \\
\hline & & & & & \multirow{2}{*}{$\begin{array}{l}\text { Strength/ } \\
\text { resistance }\end{array}$} & \multirow[t]{2}{*}{ Stiffness } & \multirow{2}{*}{$\begin{array}{l}\text { Strength/ } \\
\text { resistance }\end{array}$} & \multirow[t]{2}{*}{ Stiffness } \\
\hline & $\begin{array}{l}\text { Open } \\
\text { loop }\end{array}$ & $\begin{array}{l}\text { Closed } \\
\text { loop }\end{array}$ & & & & & & \\
\hline Bridge et al. (2004) & No & Yes & No & $\begin{array}{l}\text { Total } \\
\text { stress }\end{array}$ & \multirow{3}{*}{\multicolumn{2}{|c|}{$\begin{array}{l}\text { Scaled by a simple constant } \\
\text { factor } \\
\text { Scaled by simple constant } \\
\text { factors } \\
\text { No }\end{array}$}} & \multirow{2}{*}{\multicolumn{2}{|c|}{$\begin{array}{l}\text { Scaled by a simple } \\
\text { constant factor } \\
\text { No }\end{array}$}} \\
\hline You et al. (2008) & Yes & No & & & & & & \\
\hline $\begin{array}{l}\text { Aubeny \& Biscontin } \\
\text { (2009) }\end{array}$ & No & Yes & & & & & & \\
\hline $\begin{array}{l}\text { Randolph \& Quiggin } \\
\text { (2009) }\end{array}$ & Yes & No & & & \multirow{4}{*}{\multicolumn{2}{|c|}{$\begin{array}{l}\text { Scaled by an exponential } \\
\text { equation } \\
\text { No } \\
\text { Accounts for degradation } \\
\text { with cycle number } \\
\text { Assumes fully remoulded } \\
\text { conditions }\end{array}$}} & & \\
\hline Voie et al. (2014) & No & Yes & & & & & & \\
\hline Zargar (2017) & Yes & No & & & & & & \\
\hline Clukey \& Zakeri (2017) & No & No & & & & & & \\
\hline Present study & \multicolumn{2}{|l|}{ Yes } & Yes & $\begin{array}{l}\text { Effective } \\
\text { stress }\end{array}$ & \multicolumn{2}{|c|}{$\begin{array}{l}\text { Full range of soil strength } \\
\text { and stiffness degradation } \\
\text { with cyclic loading }\end{array}$} & \multicolumn{2}{|c|}{$\begin{array}{l}\text { Includes effect of full or } \\
\text { partial consolidation } \\
\text { on seabed strength } \\
\text { and stiffness }\end{array}$} \\
\hline
\end{tabular}

progresses, recent experimental evidence (Yuan et al., 2017) shows that over thousands of continuous load cycles the strength and stiffness can recover and surpass the initial values, due to consolidation.

These effects are potentially important in design, as noted in a recent review of the state of knowledge of SCR behaviour at the TDZ (Clukey et al., 2017): (a) variations in seabed resistance and stiffness due to consolidation may have a significant influence on the fatigue life; $(b)$ reduction in the uncertainty in fatigue assessments is vital, since many in-service SCRs are reaching the limit of their initial design life.

This paper summarises recent SCR-seabed stiffness measurements and compares them with results from effective stress analyses of vertical SCR-seabed interaction at the TDZ. The analyses are based on an effective-stress framework outlined in Zhou et al. (2019) that accounts for changing soil strength due to changes in excess pore water pressure. As applied to an SCR at the TDZ, the main features of the new analysis, which extends existing models (as outlined in Table 1) are listed below.

(a) The changing seabed strength is captured by calculating the variation in excess pore pressure generated during undrained shearing.

(b) The framework is defined with sufficient generality that it can be applied to scenarios that are load controlled, displacement controlled or a mixed sequence, such that it allows realistic simulation of 'whole-life' cyclic loading histories of SCRs undergoing vertical movement in the TDZ.

(c) A non-linear load-displacement model is used to calculate the mobilisation of the strength and limiting 
resistance, therefore giving the variation in stiffness. The load-displacement relationship uses a changing tangent stiffness that can predict SCR-seabed interaction during initial penetration, extraction and repenetration. (d) An additional reduction in soil strength due to the effect of water entrainment can be added into the analysis by migrating the fully remoulded strength line (RSL) to reflect higher degradation in soil strength.

After introducing the framework, including application to an SCR in the TDZ, the paper assesses its merit in describing long-term SCR-seabed stiffness changes at the TDZ through retrospective simulation of SCR centrifuge tests in normally consolidated kaolin clay reported in Yuan et al. (2017).

\section{DETAILS OF MODEL ANALYSIS \\ Introducing the effective stress framework}

The analysis considers vertical SCR-seabed interaction so the soil is idealised as a one-dimensional column - in an extension of the widely used oedometer method for foundation settlement. The one-dimensional soil domain is discretised, and the vertical effective stress and soil strength are calculated at each soil horizon throughout the loading sequence. Notation for this study is presented in Fig. 1.

The framework is described within the context of an SCR undergoing a history of cyclic vertical motion at the TDZ, as shown in Fig. 2. To facilitate the calculation, the SCR motion is idealised as episodic, with cycles of a penetration and extraction event (Fig. 2(a)) followed by a 'no-motion' event, during which excess pore water pressure dissipates (Fig. 2(b)).

Undrained cyclic motion leads to remoulding of the seabed, with an associated reduction in seabed strength. This loss in strength is recognised as a reduction in effective stress following excess pore water pressure generation. With accumulation of excess pore pressure, $u_{\mathrm{e}}$, the vertical effective stress, $\sigma_{\mathrm{v}}^{\prime}$, moves towards the fully remoulded strength line (denoted RSL) at constant specific volume for a fully undrained condition. This is represented by the path $\mathrm{A}-\mathrm{B}$ on Fig. 2(a), where point B represents a fully remoulded state. During the subsequent consolidation period, dissipation of excess pore pressure will result in an increase in effective stress, $\sigma_{\mathrm{v}}^{\prime}$, and reduction in specific volume, $v$, represented in Fig. 2(b) by the path $\mathrm{B}-\mathrm{C}^{\prime}$ for partial consolidation and the path B-C for full consolidation.

Repenetration of the SCR (Fig. 2(c)) will cause regeneration of excess pore pressure that will reduce $\sigma_{\mathrm{v}}^{\prime}$ to a higher limiting value (point D on the RSL, see Fig. 2(c)) than during the initial penetration due to the reduction in $v$ associated with the previous consolidation phase. The increase in $\sigma_{\mathrm{v}, \mathrm{RSL}}^{\prime}$ and reduction in $v$ (point $\mathrm{B}$ relative to point $\mathrm{D}$ on Fig. 2(c)) results in an increase in soil strength, $s_{\mathrm{u}}$. As the number of episodes of penetration, reconsolidation and repenetration increases (case I in Fig. 2(d)), the magnitude of $u_{\mathrm{e}}$ reduces with progressively diminishing increases in $\sigma_{\mathrm{v}, \mathrm{RSL}}^{\prime}$, and hence regain in $s_{\mathrm{u}}$. Hence, the limiting state is when there are no further changes in pore pressure, such that the undrained shear strength is equal to the equivalent drained value.

In reality the SCR at the TDZ may be subjected to continuous rather than episodic cyclic loading. This is handled by the framework by running the shearing and consolidation steps in sequence with the associated changes in vertical effective stress being very small for every penetration-extraction event. This is represented in Fig. 2(d) (case II) by the effective stress path $\mathrm{A}-\mathrm{B}^{\prime}-\mathrm{C}^{\prime}$ for long-term continuous cyclic undrained shearing, which like the path A-B-C for episodic cyclic undrained shearing, eventually approaches the limiting state.

\section{Formulating the framework}

The analytical components of the effective stress framework are briefly outlined in the following sub-sections, with more details of the framework provided in Zhou et al. (2019).

Excess pore pressure generation. Shear-induced excess pore pressure, $u_{\mathrm{e}}(\hat{z})(\hat{z}=z / D$, where $z$ is soil depth and $D$ is SCR diameter), generated by undrained penetration is linked to an (absolute) cumulative shear strain, $\varepsilon(\hat{z})$, at each soil horizon (Zhou et al., 2019). In the present approach, the rate of excess pore pressure generation is close to zero as the vertical effective stress approaches the RSL. The rate of excess pore pressure generation can be expressed as

$$
\begin{aligned}
\frac{\delta u_{\mathrm{e}}(\hat{z})}{\delta \varepsilon(\hat{z})} & =\frac{\chi}{\varepsilon_{99}}\left[\frac{u_{\mathrm{e}, \mathrm{r}}(\hat{z})}{u_{\mathrm{e}, \max }(\hat{z})}\right]^{p} \\
& =\frac{\chi}{\varepsilon_{99}}\left[\frac{\sigma_{\mathrm{v}}^{\prime}(\hat{z})-\sigma_{\mathrm{v}, \mathrm{RSL}}^{\prime}(\hat{z})}{\sigma_{\mathrm{v}, \mathrm{NCL}}^{\prime}(\hat{z})-\sigma_{\mathrm{v}, \mathrm{RSL}}^{\prime}(\hat{z})}\right]^{p}
\end{aligned}
$$

where $\varepsilon_{99}$ is the characteristic shear strain associated with a degree of remoulding equal to $99 \%$ (meaning a $99 \%$ reduction in strength from initial to fully remoulded, for an overconsolidation ratio, $\mathrm{OCR}=1) ; p$ is a constant power that affects the shape of the pore pressure generation; $\chi$ is a characteristic pressure that varies with specific volume, $v ; u_{\mathrm{e}, \mathrm{r}}$ is the remaining excess pore pressure defined as the distance between the current effective stress, $\sigma_{\mathrm{v}}^{\prime}$, and the effective stress on the RSL, $\sigma_{\mathrm{v}, \mathrm{RSL}}^{\prime}$, (shown in Fig. 3); and $u_{\mathrm{e} \text {,max }}$ is the maximum potential excess pore pressure, $u_{\mathrm{e}, \max }=\sigma_{\mathrm{v}, \mathrm{NCL}}^{\prime}-\sigma_{\mathrm{v},}^{\prime}$ RSL (where $\sigma_{\mathrm{v}, \mathrm{NCL}}^{\prime}$ is the vertical effective stress on the normal compression line (NCL)). The vertical effective stress on the RSL, $\sigma_{\mathrm{v}, \mathrm{RSL}}^{\prime}$, can be expressed directly in terms of the initial specific volume as

$$
\begin{aligned}
\sigma_{\mathrm{v}, \mathrm{RSL}}^{\prime}(\hat{z})= & \left(\frac{s_{\mathrm{u}}}{\sigma_{\mathrm{v} 0}^{\prime}}\right)_{\mathrm{NC}} \frac{\sigma_{\mathrm{v} 0}^{\prime}(\hat{z})}{\Phi S_{\mathrm{t}}} \\
& \exp \left(\frac{\Lambda\left\{\Gamma_{\mathrm{NCL}}-v_{\text {initial }}(\hat{z})-\lambda \ln \left[\sigma_{\mathrm{v} 0}^{\prime}(\hat{z})\right]\right\}}{\lambda-\kappa}\right)
\end{aligned}
$$

where $\left(s_{\mathrm{u}} / \sigma_{\mathrm{v} 0}^{\prime}\right)_{\mathrm{NC}}$ is the normally consolidated undrained strength ratio; $\Lambda$ is the plastic volumetric strain ratio; $\Gamma_{\mathrm{NCL}}$ is the specific volume at $\sigma_{\mathrm{v}}^{\prime}=1 \mathrm{kPa}$ on the NCL; $v_{\text {initial }}$ is the initial specific volume; $\kappa$ is the gradient of the unloadingreloading line (URL); $\lambda$ is the gradient of the NCL; $S_{\mathrm{t}}$ is the soil sensitivity; and $\Phi$ is a lumped strength parameter (described later).

The model is defined such that the changing seabed strength during cycles of penetration and extraction varies in the manner seen in cyclic penetrometer tests (e.g. Hodder et al., 2009). During penetration or extraction, a full passage of a soil element entirely into and out of the zone results in a cumulative (absolute) shear strain increase of $\Delta \varepsilon=400 \%$ (Einav \& Randolph, 2005).

Consolidation process. The initial magnitude of excess pore pressure generated by an undrained penetration event thereafter is denoted as $u_{\mathrm{e}, \mathrm{i}}(\hat{z})$, which is defined at the beginning of every pause period. Dissipation of excess pore pressure during consolidation is described by a simple hyperbolic model (Chatterjee et al., 2013; Zhou et al., 2019), which can be expressed in rate form as

$$
\frac{\delta u_{\mathrm{e}}(\hat{z})}{\delta t}=-\frac{u_{\mathrm{e}, \mathrm{i}}(\hat{z}, t) c_{\mathrm{v}}^{m} t^{m-1}\left(D^{2} T_{50}\right)^{m} m}{\left[\left(D^{2} T_{50}\right)^{m}+\left(c_{\mathrm{v}} t\right)^{m}\right]^{2}}
$$

where $t$ is the period of (consolidation) time between the penetration and extraction of an SCR at any given depth; $c_{\mathrm{v}}$ is 

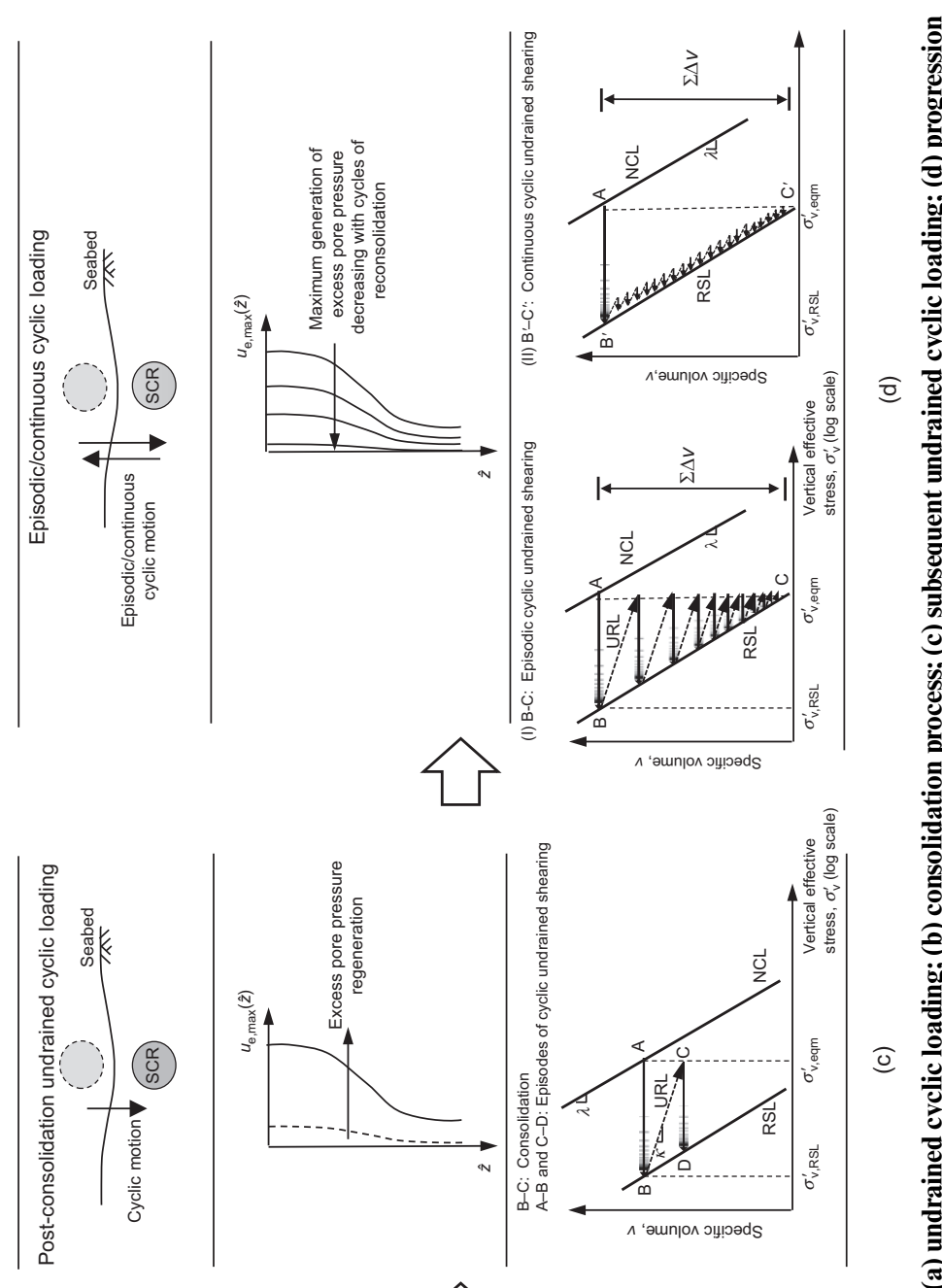

을
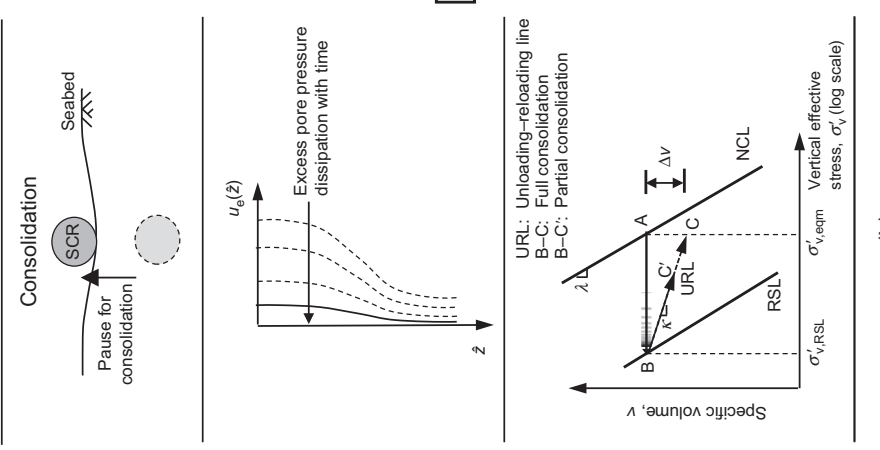

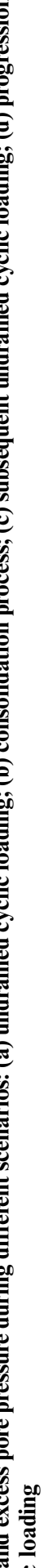
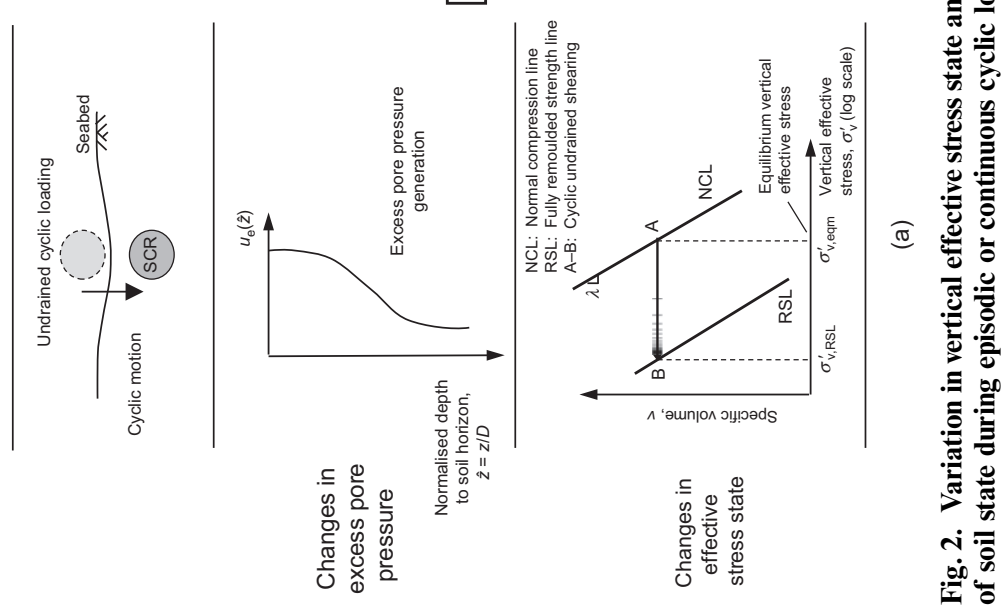


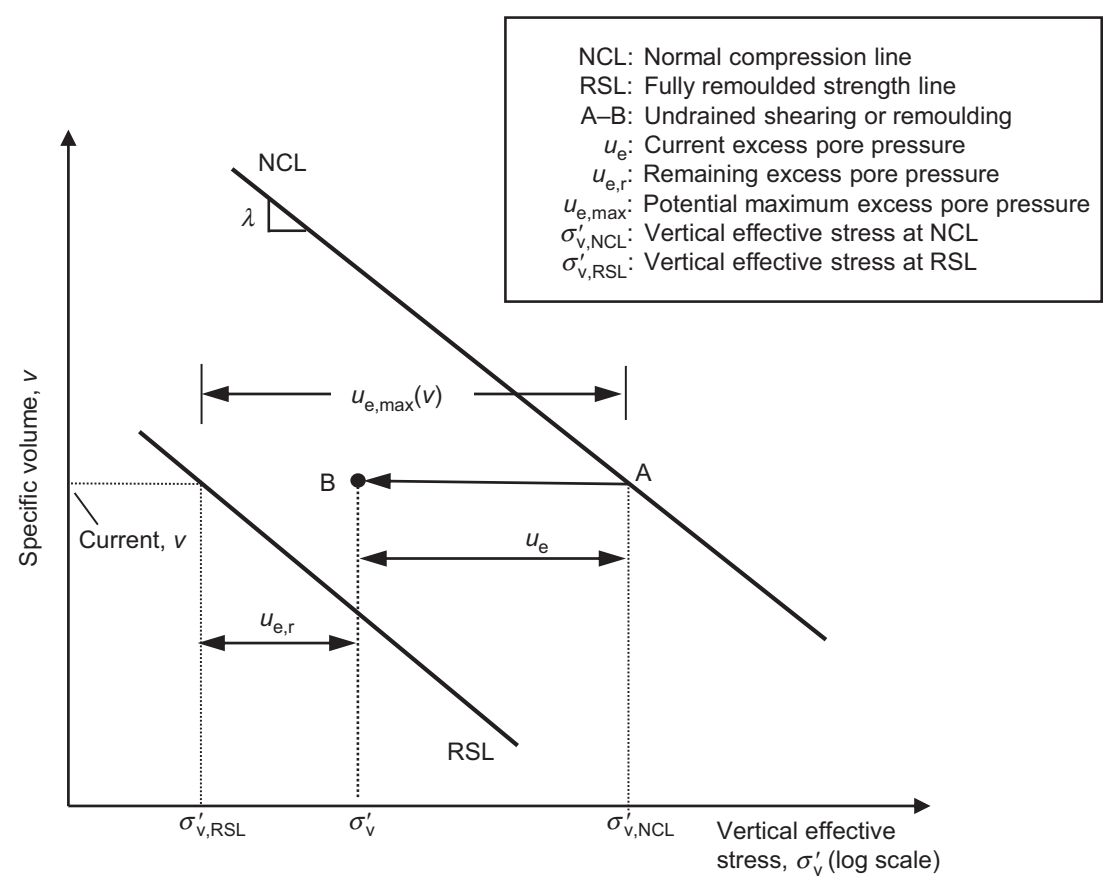

Fig. 3. Definition of maximum excess pore pressure (source: Zhou et al. (2019))

the coefficient of vertical consolidation; $m$ is a constant that controls the shape of the dissipation response; and $T_{50}$ is the dimensionless time factor for $50 \%$ dissipation of the initial excess pore pressure.

As noted earlier, excess pore pressure dissipation results in a reduction in specific volume and a rise in vertical effective stress towards the equilibrium effective stress, $\sigma_{\text {eqm }}^{\prime}(\hat{z})$ as shown in Fig. 2(b). The associated change in specific volume, $\Delta v(\hat{z})$, can be obtained from the change in vertical effective stress, $\Delta \sigma_{\mathrm{v}}^{\prime}(\hat{z})$ (equal to the dissipated excess pore pressure), expressed as

$$
\Delta v(\hat{z})=-\kappa \ln \left[\frac{\sigma_{\mathrm{v}}^{\prime}(\hat{z})+\Delta \sigma_{\mathrm{v}}^{\prime}(\hat{z})}{\sigma_{\mathrm{v}}^{\prime}(\hat{z})}\right]
$$

Soil strength response. The undrained shear strength, $s_{\mathrm{u}}(\hat{z})$, at each soil horizon is simply calculated from the vertical effective stress by way of a lumped strength parameter, $\Phi$, given by

$$
s_{\mathrm{u}}(\hat{z})=\Phi \sigma_{\mathrm{v}}^{\prime}(\hat{z})
$$

where $\sigma_{\mathrm{v}}^{\prime}(\hat{z})=\sigma_{\mathrm{v}, \text { eqm }}^{\prime}(\hat{z})-u_{\mathrm{e}}(\hat{z})$. The lumped strength parameter could be assigned a peak value that decays to a steady value with cumulative shear strain to capture effects from cementation or bonding, over-consolidation, destructuration and changes in $K_{0}$ through shearing events (White \& Hodder, 2010; Hodder et al., 2013; Zhou et al., 2019).

The shear strength that governs soil resistance is obtained from a strength influence function, $v_{\mathrm{s}}(\hat{z})$. This zone is defined by a triangular function extending by a distance, $\alpha$, above and below the centreline of the SCR. The averaged undrained shear strength, $s_{\mathrm{u}, \mathrm{av}}$, at the current embedment of the SCR, $\hat{z}_{\mathrm{e}}$ is

$$
s_{\mathrm{u}, \mathrm{av}}=\int_{\hat{z}_{\mathrm{e}}-\alpha}^{\hat{z}_{\mathrm{e}}+\alpha} s_{\mathrm{u}}(\hat{z}) v_{\mathrm{s}}(\hat{z}) \mathrm{d} z
$$

Changing seabed stiffness and mobilisation of soil strength. The mobilisation of seabed strength is linked to average undrained shear strength, $s_{\mathrm{u}, \mathrm{av}}$, and is captured by a nonlinear model, similar to the form used for $p-y$ or $t-z$ curves for pile-soil interaction. The non-linear model uses a changing tangent stiffness related to the mobilised soil strength, $s_{\mathrm{u}, \mathrm{mob}}$. Stiffness will be high as motion begins in a new direction, and ensures the soil strength asymptotically approaches the (spatially averaged) available soil strength. The incremental change in normalised soil strength during mobilisation, $\delta\left(s_{\mathrm{u}, \mathrm{mob}} / s_{\mathrm{u}, \mathrm{av}}\right)$, is expressed as

$$
\delta\left(\frac{s_{\mathrm{u}, \mathrm{mob}}}{s_{\mathrm{u}, \mathrm{av}}}\right)=\delta(\hat{z}) K
$$

in which the effective tangent stiffness, $K$, is gradually reduced according to the proportion of the change in mobilised strength that has occurred (including any unloading and reloading). After any reversal, the potential normalised change is defined as $\left(\left|\Delta s_{\mathrm{u}, \max }\right| / s_{\mathrm{u}, \text { av }}\right)$ and lies in the range $0-2$, and the current normalised change is given by $\left(\left|\Delta s_{\mathrm{u}, \mathrm{mob}}\right| / s_{\mathrm{u}, \text { av }}\right)$ and lies in the range from -1 (fully mobilised soil strength during extraction) to 1 (fully mobilised soil strength during penetration), as shown in Fig. 4. The effective tangent stiffness is expressed as

$$
K=\left\{1-\left[\frac{\Delta\left(s_{\mathrm{u}, \operatorname{mob}} / s_{\mathrm{u}, \mathrm{av}}\right)}{\Delta\left(s_{\mathrm{u}, \max } / s_{\mathrm{u}, \mathrm{av}}\right)}\right]^{\zeta}\right\} K_{\max }
$$

where $\zeta$ is the power law parameter to account for the rate of change in tangent stiffness and is generally in the range from $0 \cdot 1$ to $0 \cdot 5$, and $K_{\max }$ is the maximum tangent stiffness that is adopted since the last reversal in penetration or extraction. Noting that load cycles may be fully or partially mobilised (see Fig. 4(a)), the selection of $K_{\max }$ can be assigned on the basis of variation in $\left(\left|\Delta s_{\mathrm{u}, \max }\right| / s_{\mathrm{u}, \mathrm{av}}\right)$ (e.g. as shown by the simple linear dependence on Fig. 4(b)). The generality of the framework allows for progressive motion in one-way and two-way cyclic loading with changing soil tangent stiffness (see Fig. 4). 

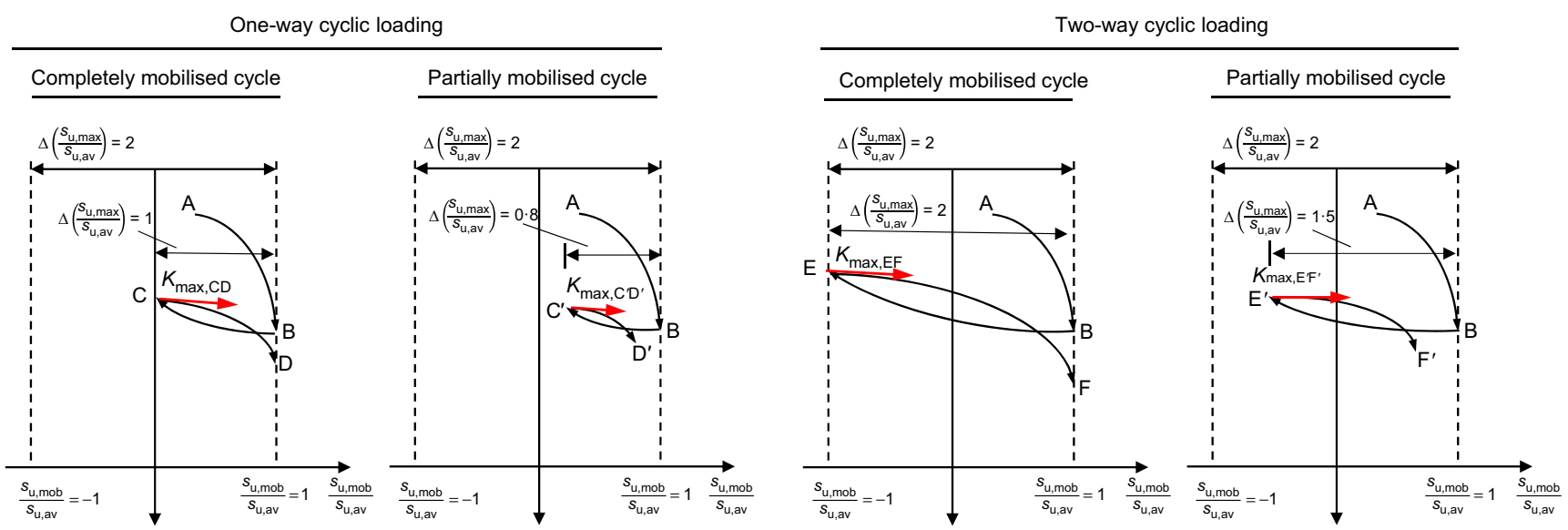

(a)

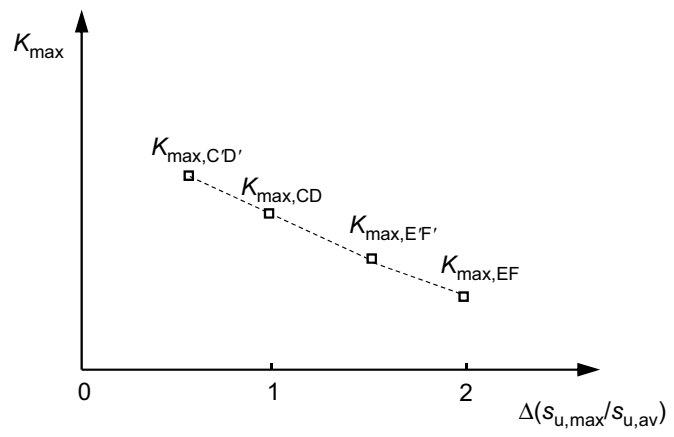

(b)

Fig. 4. Mobilisation of soil strength under complex motion: (a) complete and partial cycles under one-way and two-way cyclic loading; (b) corresponding maximum tangent stiffness

Application of the framework to an element of SCR

at the TDZ

Application to an element of SCR interacting with the seabed requires that a depth profile of excess pore pressure is generated for each time step, allowing for a depth profile for effective stress, from which the soil strength and hence the SCR penetration resistance, $q$, is calculated. The calculation procedure is presented in Fig. 5 and described below.

The depth zone over which excess pore pressure is generated due to the passage of the SCR element within the seabed is considered in terms of the incremental shear strain at each soil horizon, $\delta \varepsilon(\hat{z})$. This is quantified by an strain influence function, $\mu(\hat{z})$, when the soil element is close to the SCR within the strain influence zone (see Fig. 5(b)), and expressed as

$$
\delta \varepsilon(\hat{z})=4 \mu(\hat{z}) \delta \hat{z}_{\mathrm{m}}
$$

where $\delta \hat{z}_{\mathrm{m}}$ is the incremental embedment of the SCR. The strain influence zone is considered as a triangular shape with limits that extend a normalised distance, $\beta$, above and below the SCR centreline. If the soil horizon is outside the influence zone, then $\mu(\hat{z})=0$, and the soil horizon is unaffected by the current SCR displacement. Integration of the strain rate over the influence zone results in a shear total strain, $\Delta \varepsilon=400 \%$ (based on Einav \& Randolph (2005)). Using equation (1), the vertical spatial distribution of excess pore pressure at each soil horizon, $u_{\mathrm{e}}(\hat{z})$, is calculated and shown in Fig. 5(c). Vertical effective stress, $\sigma_{\mathrm{v}}^{\prime}(\hat{z})$, is then calculated in response to any change in excess pore pressure (Fig. 5(d)), allowing for depth profiles of average soil strength and mobilised soil strength (Fig. 5(e)).

The penetration resistance on the SCR element, $q$, is the sum of seabed resistance, $q_{\mathrm{s}}($ Fig. $5(\mathrm{~g}))$, and soil buoyancy, $q_{\mathrm{b}}$
(Fig. 5(h))

$$
q(\hat{z})=q_{\mathrm{s}}(\hat{z})+q_{\mathrm{b}}(\hat{z})
$$

in which

$$
q_{\mathrm{s}}(\hat{z})=N_{\mathrm{c}} s_{\mathrm{u}}
$$

and

$$
q_{\mathrm{b}}(\hat{z})=f_{\mathrm{b}} A_{\mathrm{s}} \gamma^{\prime} \frac{1}{D}
$$

$s_{\mathrm{u}}$ in equation (11) is the undrained shear strength predicted by the framework and $N_{\mathrm{c}}$ is a bearing capacity factor (Fig. 5(f)) that varies with depth as the failure mechanism transitions from shallow to deep. This depth variation is allowed for here through (Randolph \& White, 2008a; Aubeny \& Biscontin, 2009; Merifield et al., 2009; White et al., 2010)

$$
N_{\mathrm{c}}=a(\hat{z})^{b}
$$

where the constants $a$ and $b$ are selected for a rough surface as $a=7 \cdot 1$ and $b=0.33$ for $\hat{z} \leq 0.75$ (Merifield et $a l ., 2009$ ), and $a=6$ and $b=0.15$ for $\hat{z}>0.75$ (Randolph \& White, 2008a).

The soil buoyancy term, $q_{\mathrm{b}}$, in equation (12) is calculated as the product of the effective unit weight of soil, $\gamma^{\prime}$, and the (normal) cross-sectional area of the embedded segment of the SCR, $A_{\mathrm{s}}$ (Hodder et al., 2009; Merifield et al., 2009). An additional effect of soil heave is captured by a factor, $f_{\mathrm{b}}$, and it is assumed that $f_{\mathrm{b}}$ decreases linearly from $1 \cdot 3$ (for soft clay) to unity at a critical depth where the failure mechanism is localised to the SCR (White et al., 2010). 

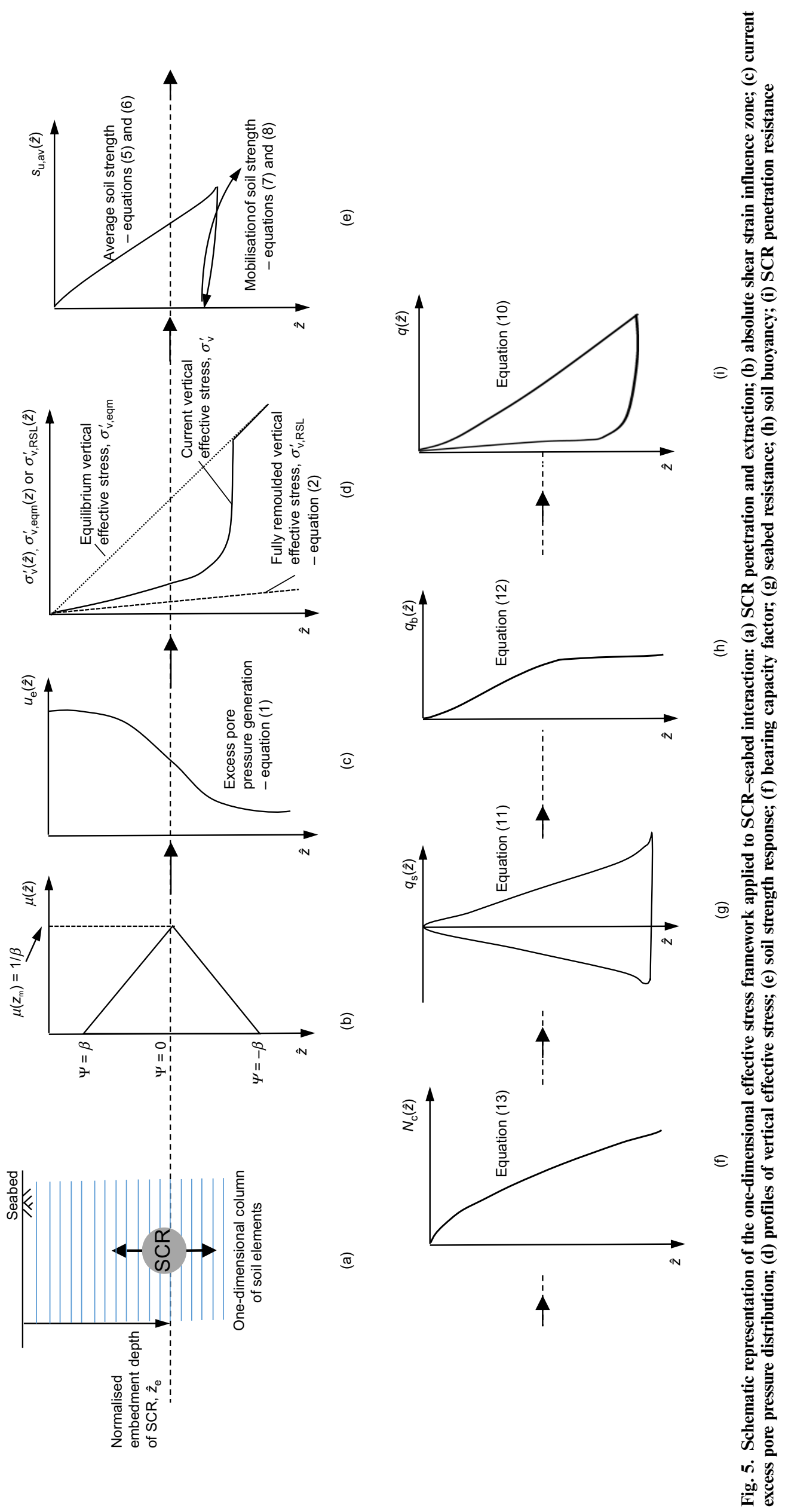


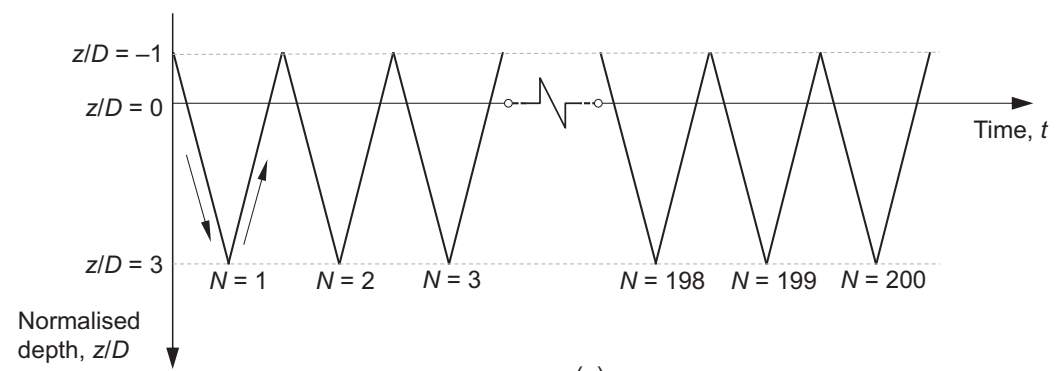

(a)

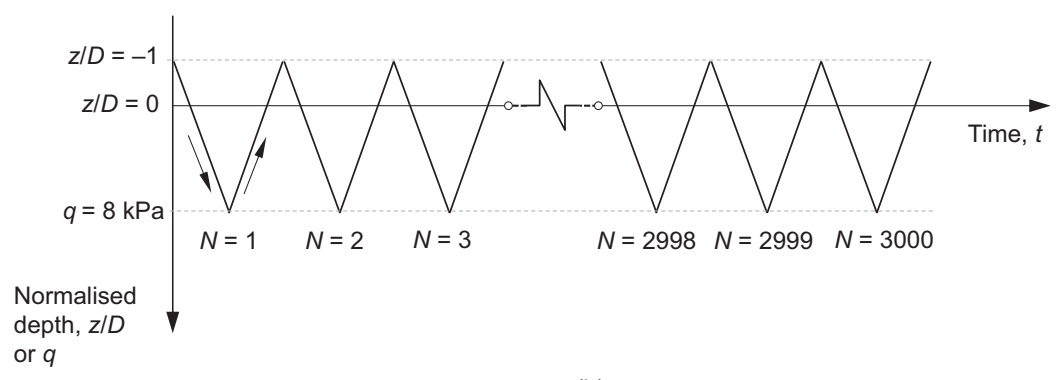

(b)

Fig. 6. Displacement - time histories of: (a) short-term SCR test; (b) long-term SCR test (from Yuan et al., 2017)

\section{EFFECTIVE STRESS ANALYSIS OF SCR-SEABED INTERACTION}

The SCR element tests reported by Yuan et al. (2017) are summarised here, and simulated using the effective stress model. These tests serve as the best means of assessing the merit of the method as they involve up to 3000 cycles of SCR penetration and extraction, over a period of time that is sufficient to observe both the reduction and subsequent increase in soil strength and consequently SCR-seabed vertical stiffness. The tests were conducted in normally consolidated kaolin clay in a geotechnical centrifuge at $50 \mathrm{~g}$. The SCR was modelled using a segment of pipe with a diameter of $20 \mathrm{~mm}$ ( $1 \mathrm{~m}$ at prototype scale) and a length of $120 \mathrm{~mm}$ (6 $\mathrm{m}$ at prototype scale).

Two tests are considered here, time histories for which are shown in Fig. 6. The first was a 'short-term' test, in which the SCR was penetrated from a normalised depth of $\hat{z}=-1$ (i.e. from one diameter above the mudline) to $\hat{z}=3$ for 200 cycles. The second was a 'long-term' test in which the SCR was penetrated from a normalised depth of $\hat{z}=-1$ to a depth equivalent to an applied pressure, $q_{\mathrm{p}}=8 \mathrm{kPa}$ for 3000 cycles. In each test the model SCR was penetrated and extracted at a velocity of $2.5 \mathrm{~mm} / \mathrm{s}$ (at model scale), which was considered sufficient to generate undrained conditions for the two tests. Further details of the tests are provided in Yuan et al. (2017).

\section{Selection of framework parameters}

The model parameters are summarised in Table 2. The geometry and soil parameters were all known or measured, and are reported in Yuan et al. (2017). The critical state parameters were initially established by Stewart (1992) for the kaolin clay used in these model tests, and have since been adopted for numerical simulations of more recent model tests in the same clay kaolin clay (e.g. Chatterjee et al., 2013; Feng \& Gourvenec, 2016). $\left(s_{\mathrm{u}} / \sigma_{\mathrm{v} 0}^{\prime}\right)_{\mathrm{NC}}$ is quantified from the strength measured during initial penetration. For the Yuan et al. $(2017)$ model tests, $\left(s_{\mathrm{u}} / \sigma_{\mathrm{v} 0}^{\prime}\right)_{\mathrm{NC}}=0 \cdot 16$, established from a ball penetrometer test using a bearing factor of $10 \cdot 5$ (Martin \& Randolph, 2006) and a measured average effective soil unit weight, $\gamma^{\prime}=6 \mathrm{kN} / \mathrm{m}^{3}$. The ball penetrometer test also involved a cyclic remoulding phase, from which the soil sensitivity was determined to be $S_{\mathrm{t}}=2 \cdot 5$.

For excess pore pressure generation, the parameters used in equation (1) are the characteristic strain, $\varepsilon_{99}$, and the rate of excess pore pressure generation control parameter, $p$. These were established as $\varepsilon_{99}=100$ and $p=2.6$ in Zhou et al. (2019) by fitting the degradation of soil strength measured in a T-bar penetration test in normally consolidated University of Western Australia (UWA) kaolin clay. For consolidation, the parameters used in equation (3) are the dimensionless time for $50 \%$ consolidation, $T_{50}$ and the embedment level parameter, $m$. These have been taken as $T_{50}=0 \cdot 09$, consistent with results from numerical analyses of an embedded pipeline reported by Chatterjee et al. (2013), and $m=1 \cdot 4$, higher than $m=1.05$ in Chatterjee et al. (2013). This is selected because Chatterjee et al. (2013) showed that $m$ increases with embedment depth, and the maximum SCR embedment depth is closer to one diameter rather than the maximum half diameter in the Chatterjee et al. (2013) simulations. The coefficient of consolidation, $c_{\mathrm{v}}$, was obtained from Rowe cell consolidation tests on UWA kaolin clay (House et al., 2001), where the dependence on vertical effective stress level, $\sigma_{\mathrm{v}}^{\prime}$, can be described as

$$
c_{\mathrm{v}}=\left(0 \cdot 3+0 \cdot 16 \sigma_{\mathrm{v}}^{\prime}\right)^{0 \cdot 47}
$$

where $c_{\mathrm{v}}$ is in units of $\mathrm{m}^{2} /$ year and $\sigma_{\mathrm{v}}^{\prime}$ is in $\mathrm{kPa}$.

To define a shear strain influence zone and the strength influence zone for an SCR, values of $\beta=0.5$ and $\alpha=0.5$ are selected, respectively, based on the clay failure mechanism for an SCR at shallow embedment (Randolph \& White, 2008a, 2008b), while for deep embedment, values of $\beta=1$ and $\alpha=1$ are selected, consistent with previous studies (Hodder et al., 2013; Zhou et al., 2019). The critical depth where the failure mechanism transfers from shallow to deep is taken here as $z / D=2$, based on the shallow correction method outlined in White et al. (2010). It is assumed that $\beta$ and $\alpha$ increase linearly from 0.5 at the mudline to unity at this critical depth.

The maximum stiffness used in equation (8) was taken as $K_{\max }=200$, which is typical (Clukey et al., 2005, 2008; Randolph \& Quiggin, 2009) and corresponds to a soil 
Table 2. Summary of framework parameters

\begin{tabular}{|c|c|c|c|}
\hline Framework component & Parameter & Description & Value \\
\hline Geometry & $D$ & Diameter of SCR (prototype scale) & $1 \mathrm{~m}$ \\
\hline \multirow[t]{3}{*}{ Soil characteristics } & $\gamma^{\prime}$ & Effective unit weight & $6 \mathrm{kN} / \mathrm{m}^{3}$ \\
\hline & OCR & Overconsolidation ratio & \\
\hline & $S_{\mathrm{t}}$ & Sensitivity & $2 \cdot 5(4)^{*}$ \\
\hline \multirow[t]{5}{*}{ Critical state mode } & $\lambda$ & Compression index & $0 \cdot 205$ \\
\hline & $\kappa$ & Swelling index & $0 \cdot 044$ \\
\hline & $\Lambda$ & Plastic volumetric strain ratio & $0 \cdot 6$ \\
\hline & $\left(s_{\mathrm{u}} / \sigma_{\mathrm{vo}}^{\prime}\right)_{\mathrm{NC}}$ & Normally consolidated undrained strength ratio & $0 \cdot 16$ \\
\hline & $\Gamma_{\mathrm{NCL}}$ & Specific volume, $v$, at $\sigma_{\mathrm{v}}^{\prime}=1 \mathrm{kPa}$ on $\mathrm{NCL}$ & $3 \cdot 251$ \\
\hline \multirow[t]{3}{*}{ Excess pore pressure generation } & $\varepsilon_{99}$ & Cumulative shear strain parameter & $100(600)^{*}$ \\
\hline & $p$ & Shear strain rate parameter & $2 \cdot 6(2 \cdot 95)^{*}$ \\
\hline & $\beta$ & Strain influence zone extent & $0 \cdot 5 D$ \\
\hline \multirow[t]{2}{*}{ Consolidation process } & $T_{50}$ & Non-dimensional time for $50 \%$ consolidation & $0 \cdot 09$ \\
\hline & & Embedment level parameter & $1 \cdot 4$ \\
\hline \multirow[t]{4}{*}{ General soil strength and stiffness response } & $\Phi_{\text {steady }}$ & Strength parameter at steady, remoulded conditions & $0 \cdot 6$ \\
\hline & & Strength influence zone extent & $0 \cdot 5 D$ \\
\hline & $K_{\max }$ & Maximum tangent stiffness & 200 \\
\hline & $\zeta$ & Power law parameter for strength mobilisation & $0 \cdot 32$ \\
\hline
\end{tabular}

*Values in brackets consider water entrainment.

rigidity ratio of $G_{0} / s_{\mathrm{u}} \sim 300$ based on the relevant elastic and plastic solutions for half a diameter embedment (Randolph $\&$ White, 2008b; Guha et al., 2016). The power parameter, $\zeta$, in equation (8) was taken as $\zeta=0 \cdot 32$, as this provided a good match with the measured mobilisation of soil resistance during T-bar penetration in normally consolidated kaolin clay (Zhou et al., 2019). In summary, all model parameters are either derived from the strength profiles determined in Yuan et al. (2017), or have been calibrated in previous studies, and are initially applied here without modification, before further improvements are examined.

\section{Results and discussion}

Short-term SCR test. The framework calculates changes in seabed strength, which is then linked to seabed resistance, $q_{\mathrm{s}}$, through equation (11), providing a prediction of the resistance during the vertical motion (Fig. 6). As noted earlier in the paper, soil buoyancy, $q_{\mathrm{b}}$, is included, making allowance for soil heave through the factor $f_{\mathrm{b}}$ in equation (12). For soft clay, $f_{\mathrm{b}}$ may be taken as $1 \cdot 3$, reducing to unity at the critical depth of $\hat{z}=2$, as is consistent with previous studies (Merifield et al., 2009). The SCR penetration resistance is the sum of $q_{\mathrm{s}}(\hat{z})$ and $q_{\mathrm{b}}(\hat{z})$ at each soil horizon, using equation (10).

Figure 7 compares the model simulations and the measurements for the short-term test. Negative values of penetration resistance correspond to a downwards geotechnical resistance on the SCR, which is created when the SCR moves upwards. The cyclic strength degradation is illustrated in Fig. 7(a), which shows the ratio of the seabed penetration resistance at cycle number $N$ to that in the first cycle, $q_{\mathrm{s}, N} / q_{\mathrm{s}, 1}$, at a normalised depth, $\hat{z}=2$. The measurements show that the seabed penetration resistance gradually degrades to $q_{\mathrm{s}, N} / q_{\mathrm{s}, 1} \sim 0 \cdot 25$ after about 200 cycles, lower than the simulations, which provide a steady-state $q_{\mathrm{s}, N} / q_{\mathrm{s}, 1} \sim 0.42$ at $N=200$, close to $1 / S_{\mathrm{t}}$ as expected for a fully remoulded condition. However, and as noted in Yuan et al. (2017), a lower penetration resistance is to be expected for this 'mudline-breaking' test, where the continued passage of the SCR across the water-mudline interface allowed water to become entrained at the SCR-seabed interface.

This water entrainment leads to a mobilised soil strength that is lower than the nominally remoulded soil strength (e.g. that would be measured in a cyclic penetrometer test), as also noted in cyclic 'mudline-penetrating' SCR and T-bar penetrometer tests (e.g. Clukey et al., 2005; Gaudin \& White, 2009; Hodder et al., 2009), and experimental studies on suction caissons (e.g. Gaudin et al., 2014), dynamically installed anchors (e.g. Richardson et al., 2009; O'Beirne et al., 2017) and in high-rate ring-shear tests (where water was permitted to penetrate the shear zone (Tika \& Hutchinson, 1999)). The RSL defines the fully remoulded state in the framework, and $S_{\mathrm{t}}$ is the primary parameter that controls the position of the RSL through equation (2). To account for the effect of water entrainment, $S_{\mathrm{t}}$ is raised, shifting the RSL to the left, which results in a lower effective stress, and therefore strength, after remoulding.

In order to capture the additional loss in seabed strength from the water entrainment, values of $S_{\mathrm{t}}=4, \varepsilon_{99}=600$ and $p=2.95$ are used to match the experimental measurements, in which the higher $S_{\mathrm{t}}$ represents a lower (water entrained) remoulded soil strength; the higher $\varepsilon_{99}$ requires a greater level of strain to reach the fully softened condition through water entrainment, and $p$ is modified to ensure that the calculated initial shear strength gradient agrees with the measured $\sim 0.96 \mathrm{kPa} / \mathrm{m}$. The revised simulations are also shown in Fig. 7(a) and are in good agreement with the experimental measurements.

Figure 7(b) compares simulated and measured (depth) profiles of SCR penetration resistance, $q$, at cycle numbers $N=1,2,50$ and 200 , using the modified parameters that represent water entrainment. The gradient of resistance with depth reduces at $\hat{z}=1$, which is due to the non-linear increase in soil buoyancy as the SCR becomes fully embedded (i.e. over $\hat{z} \leq 1$ ). Soil buoyancy is an upwards positive resistance of approximately $5 \mathrm{kPa}$ for $\hat{z}>1$, which results in (the fully embedded) $q$ between penetration and extraction being approximately symmetrical about this offset. Fig. 7(b) shows that the framework is capable of capturing accurately the loss in both the penetration and extraction resistance during the initial 200 cycles of penetration. Over this period consolidation effects are negligible.

\section{Long-term SCR test}

\section{Modelling of the open trench}

Simulations of the long-term test required that the experimental observations of a developing open trench were accounted for in the simulations, as an additional input. As shown in Fig. 8, the trench depth, $z_{\text {trench }}$, in the experiments 


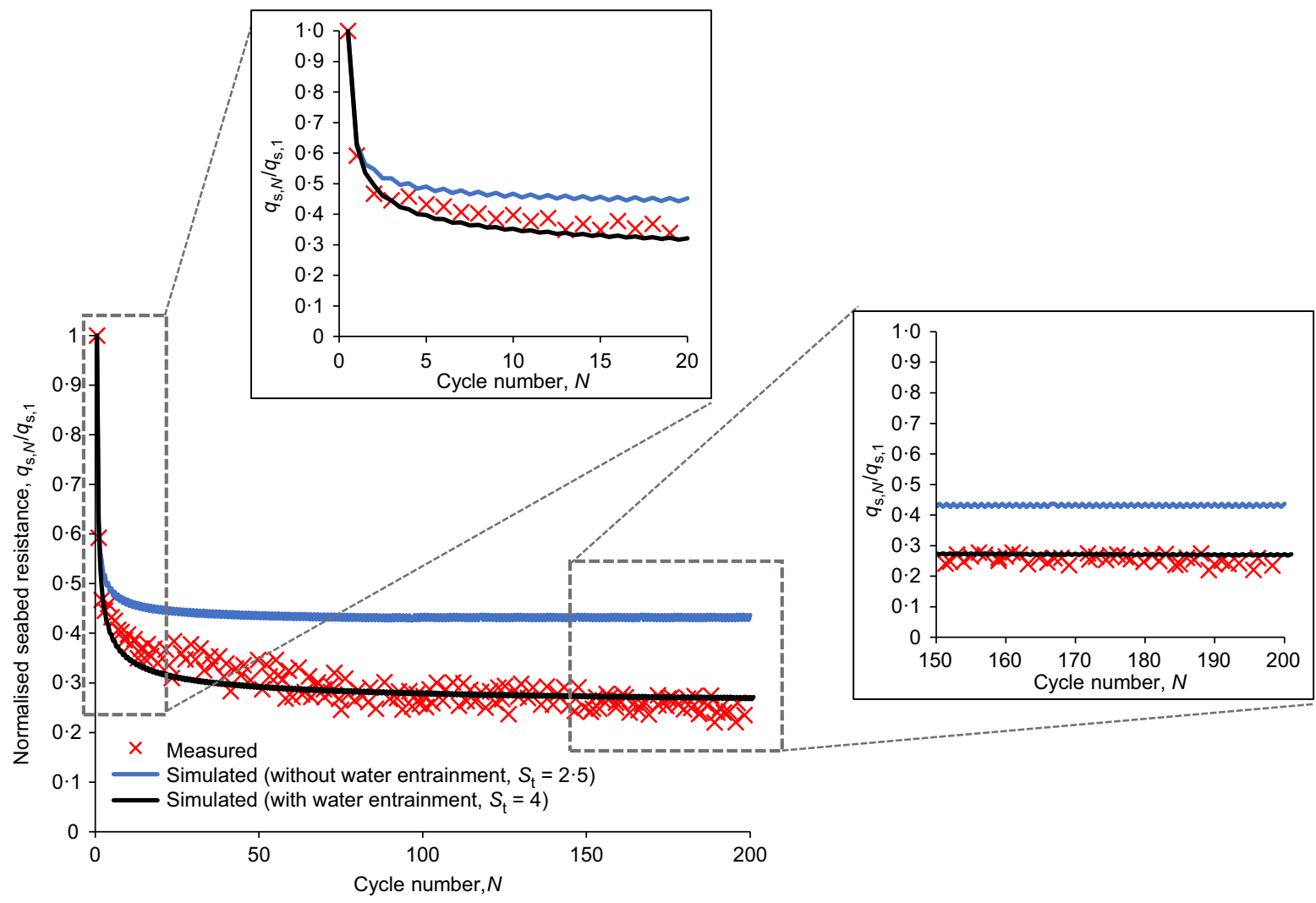

(a)

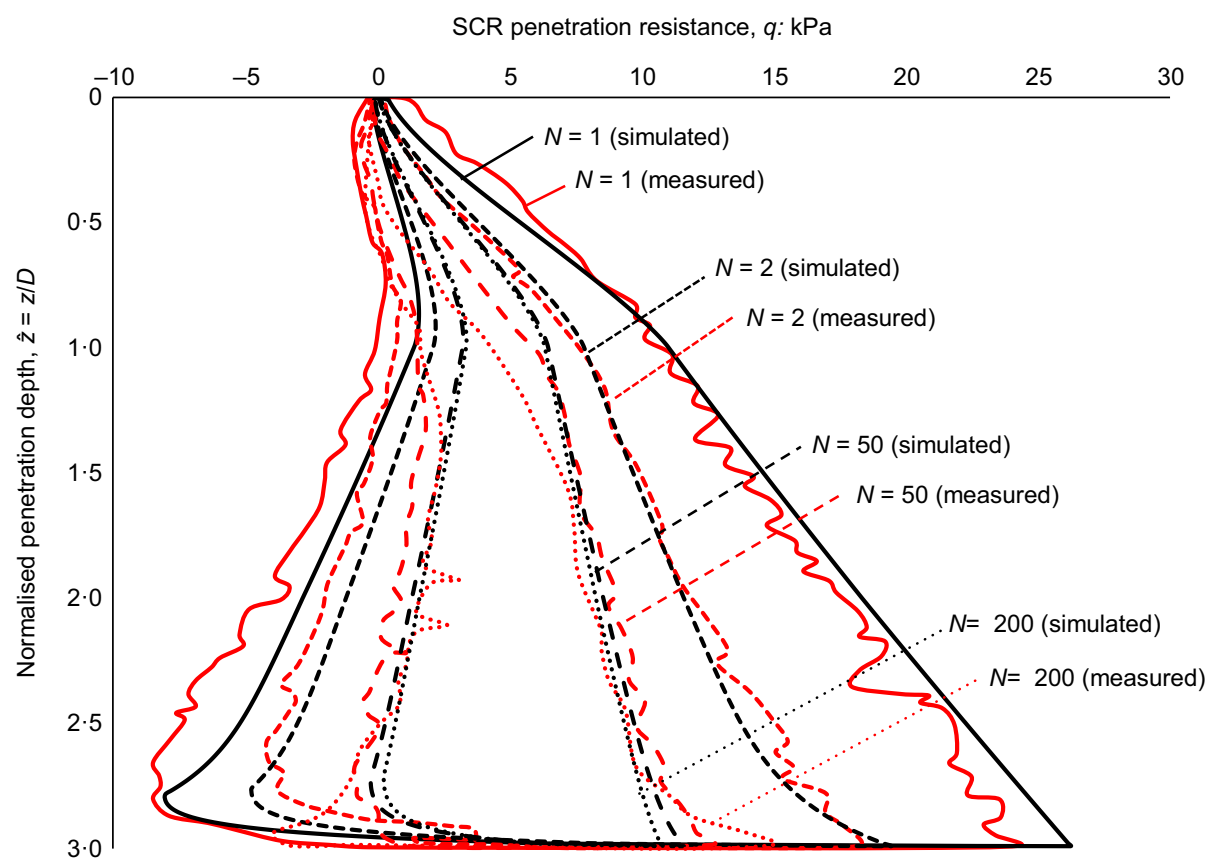

(b)

Fig. 7. Comparison of experimental and predicted $S C R$ penetration resistance during short-term test: (a) normalised seabed resistance, $q_{\mathrm{s}, N} l q_{\mathrm{s}, 1}$, at a depth of $\hat{z}=2$; (b) SCR penetration resistance profiles

increased with cycle number, reaching a temporarily stable $z_{\text {trench }} / D \sim 0 \cdot 18$ after $N=200$, before increasing to $z_{\text {trench }} / D \sim 0.67$ after the complete set of $N=3000$ cycles. The initial trench formation to about $0 \cdot 18$ times the SCR diameter is due to the lateral displacement of soil associated with the repeated passage of the SCR through the mudline. This results in heave at the mudline adjacent to the SCR, and a depression at the SCR location. The continued deepening of the trench is due to the gradual reduction in specific volume of the penetrated column of soil due to consolidation.

The evolving trench was accounted for in the simulations by defining an effective penetration depth, $z^{\prime}=z-z_{\text {trench }}$, where $z$ is the SCR penetration depth relative to the original mudline as defined earlier. Soil buoyancy is then calculated using the effective penetration depth, and values of $q_{\mathrm{b}}=0$ 


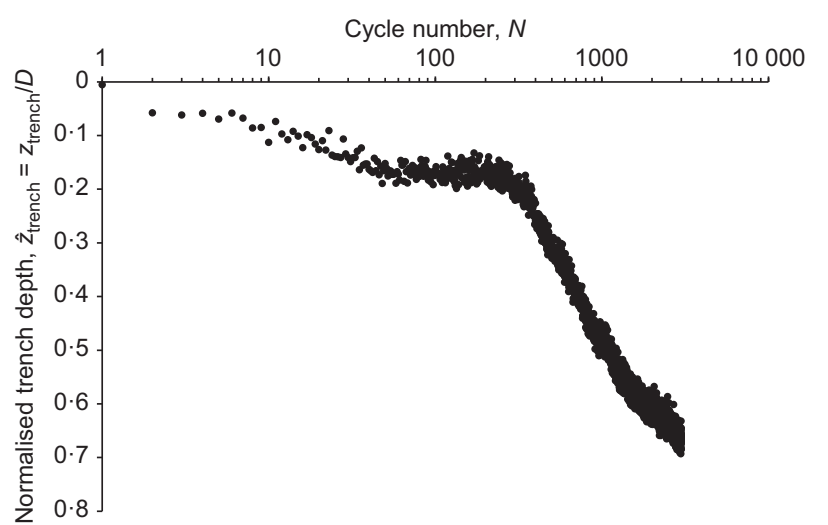

Fig. 8. Development of trench during long-term test (after Yuan et al., 2017)

and $q_{\mathrm{s}}=0$ are assigned when the SCR is below the original mudline but still above the current soil surface - that is, for $z^{\prime} \leq 0$.

\section{Variation in SCR penetration resistance}

Figure 9 compares the simulated and measured resistance profiles at different cycles. In this test the SCR was penetrated until $q=8 \mathrm{kPa}$, such that the maximum penetration resistance is similar in each profile, but is reached at different embedment depths at cycle number increases. Over the first 100 cycles (Figs 9(a)-9(d)) the penetration depth at which $q=8 \mathrm{kPa}$ increases, reflecting the remoulding and water entrainment processes that reduce soil strength. However, at higher cycle numbers $(N=1000$ to 3000 ; Figs $9(\mathrm{e})-9(\mathrm{~h}))$ the limiting penetration depth reduces as the soil strength increases through consolidation.

Over the first 100 cycles, the simulations are in remarkable agreement with the measurements for both penetration and extraction. At higher cycle numbers, the model captures well the limiting embedment depth, while slightly over-predicting $q$ during penetration at shallow embedment. However, $q$ during extraction is overestimated in the simulations at the higher cycle numbers. The simulated extraction resistance is approximately symmetrical about the soil buoyancy resistance profile, as for any given cycle the calculated seabed resistance, $q_{\mathrm{s}}$, is equal for penetration and extraction. This is consistent with the steady state that is reached during the cyclic remoulding phase of a full-flow penetrometer test, or indeed the transient steady-state resistance that was reached during the short-term SCR test in Fig. 7(a), which is why the simulations are in good agreement with both the measured penetration and extraction $q$ profiles over the first 100 cycles on Fig. 9.

The much lower measured extraction $q$ (relative to penetration) at higher cycle numbers indicates that other processes are involved during extraction. As the SCR reverses direction from penetration to extraction, $q$ initially becomes lower than $q_{\mathrm{b}}$, indicating that some reverse bearing capacity is mobilised (although by a small amount relative to the difference between $q$ and $q_{\mathrm{b}}$ during penetration). However, it appears that this resistance is rapidly lost, perhaps because suction cannot be mobilised if free water can reach the interface around the invert of the SCR. Thereafter, the uplift resistance is approximately equal to $q_{\mathrm{b}}$ for the remainder of the extraction. Although the framework does not capture this effect, the calculated SCR-seabed stiffness is unaffected as this is based solely on the penetration response.

\section{Variation in effective stress state and soil strength}

The internal variables of the simulation shown in Fig. 9 allow the changes in effective stress and strength during the long-term test to be illustrated. Fig. 10 presents the variation in calculated effective stress state and corresponding changes in undrained shear strength at $z^{\prime} / D=0 \cdot 4$ over the 3000 cycles. A number of features are observed as follows.

(a) During the first few cycles of penetration, the excess pore pressure generation is much higher than the excess pore pressure dissipation, such that the vertical effective stress state approaches the RSL.

(b) As the SCR motion is continuous, the effective stress state changes only slightly between each cycle as there is a very short reconsolidation period between the shearing events. Consequently, the effective stress path tracks close to the RSL, although closer inspection (inset in Fig. 10(a)) reveals that each cycle is associated with a small increase in vertical effective stress along the URL with the corresponding reduction in specific volume.

(c) As the cycle number increases, so too does the vertical effective stress on the RSL, such that the potential for maximum excess pore pressure generation, $u_{\mathrm{e}}=\sigma_{\mathrm{v}, \mathrm{eqm}}^{\prime}-\sigma_{\mathrm{v}, \mathrm{RSL}}^{\prime}$, progressively decreases from a maximum $u_{\mathrm{e}} \sim 2 \cdot 2 \mathrm{kPa}$ at the start of the test to $u_{\mathrm{e}} \sim 0.3 \mathrm{kPa}$ at $N=3000$. The 3000 cycles involve a duration, $t \sim 16 \mathrm{~h}$ at model scale (equivalent to $\sim 4.6$ years at prototype scale), which corresponds to a dimensionless time, $T=c_{\mathrm{v}} t / D^{2} \sim 4$ (adopting $c_{\mathrm{v}} \sim 0.85 \mathrm{~m}^{2} /$ year for $\sigma_{\mathrm{v}}^{\prime}=2.4 \mathrm{kPa}$ at a normalised depth of $z^{\prime} / D=0 \cdot 4$, by way of equation (14)). Hence, the remaining excess pore pressure after 3000 cycles, at $T \sim 4$, is equivalent to $\sim 14 \%$ of the initial maximum excess pore pressure. By way of comparison, the elastic solution for $90 \%$ dissipation for a pipeline under a maintained load at an embedment of $z^{\prime} / D=0.5$ is $T_{90} \sim 2$ (Gourvenec \& White, 2010), and an elasto-plastic solution for the same case is $T_{90} \sim 0 \cdot 7$ (Chatterjee et al., 2013). The higher $T$ to approach equilibrium in these simulations is because pore pressure is being successively generated and dissipated to reach the densified state where limited further pore pressure can be generated. In contrast, the conventional dissipation solutions indicate the time required for a single dissipation event.

(d) Figure 10(b) shows the change in undrained shear strength at $z^{\prime} / D=0.4$ over the 3000 cycles. The strength decreases (by a factor of $\sim S_{\mathrm{t}}$ ) from an initial value of $s_{\mathrm{u}}=0 \cdot 4 \mathrm{kPa}$ at $N=1$ to $s_{\mathrm{u}}=0.13 \mathrm{kPa}$ at $N=50$, due to the generation of excess pore pressure with practically no consolidation-induced reduction in specific volume (as shown by Fig. 10(a)). Over the remaining 2500 cycles, $s_{\mathrm{u}}$ increases to $\sim 1 \cdot 2 \mathrm{kPa}$, with an extended analysis to $N=10000$ giving $S_{\mathrm{u}} \sim 1.4 \mathrm{kPa}$, which corresponds to $\sim 99 \%$ consolidation. Hence, the (near) limiting undrained shear strength is approximately 3.5 times the initial value, identical to the ratio of drained to undrained strength for UWA kaolin clay as inferred from penetrometer tests (Colreavy et al., 2016).

Variation in seabed penetration stiffness

As noted earlier in the paper, a key design issue for assessing the fatigue life of an SCR at the TDZ is selecting an appropriate value for the SCR penetration stiffness, $k_{\mathrm{s}}$, given by

$$
k_{\mathrm{s}}=\frac{q_{\mathrm{max}}}{z^{\prime}}
$$

where $q_{\max }$ is the maximum SCR penetration resistance during each cycle of penetration linked to the (changing) soil strength through equations (10) and (11). 

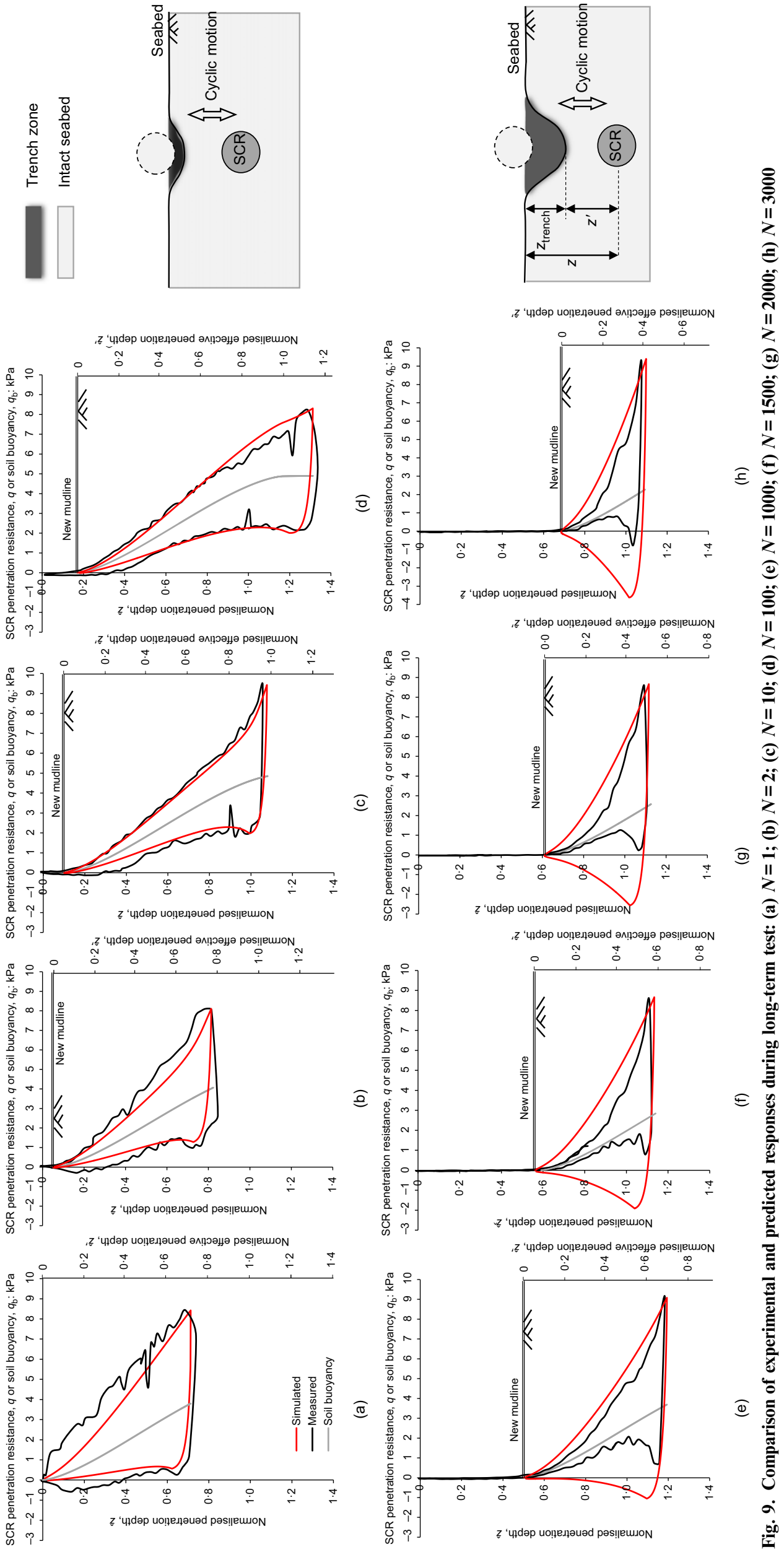


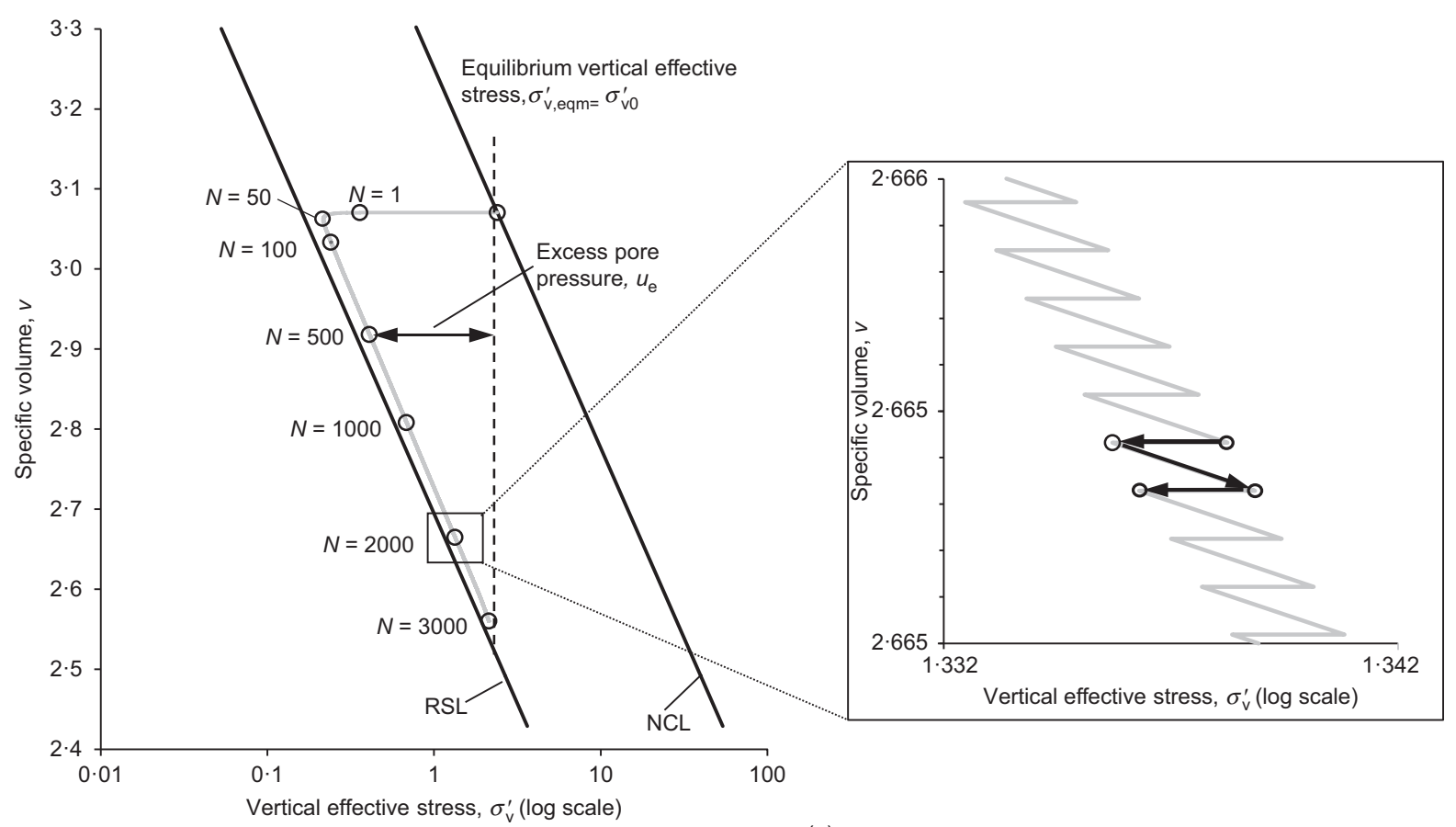

(a)

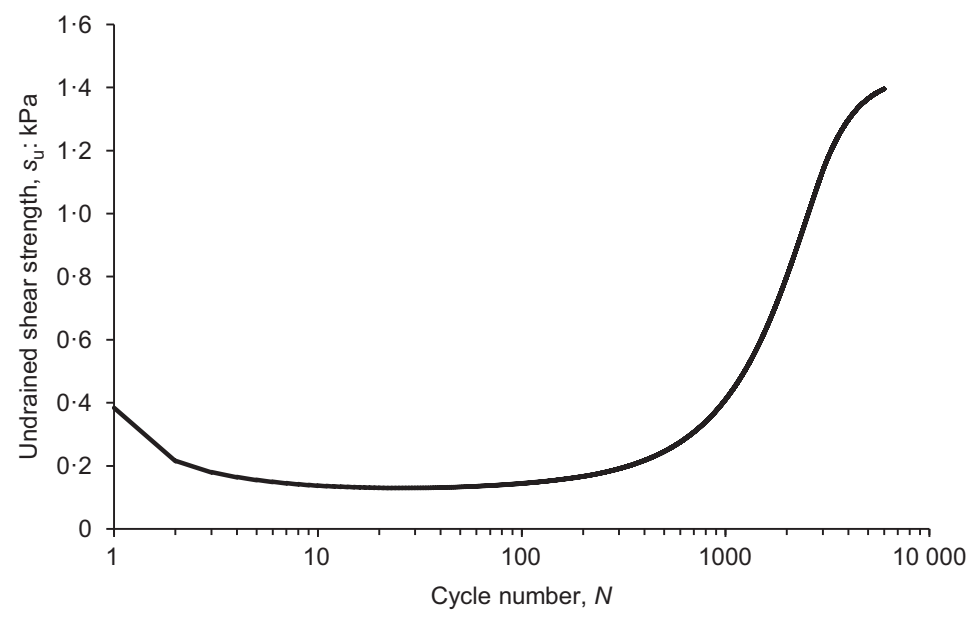

(b)

Fig. 10. Calculated soil response at $z^{\prime}=0 \cdot 4$ in the long-term test: (a) variation in effective stress state; (b) changing undrained shear strength

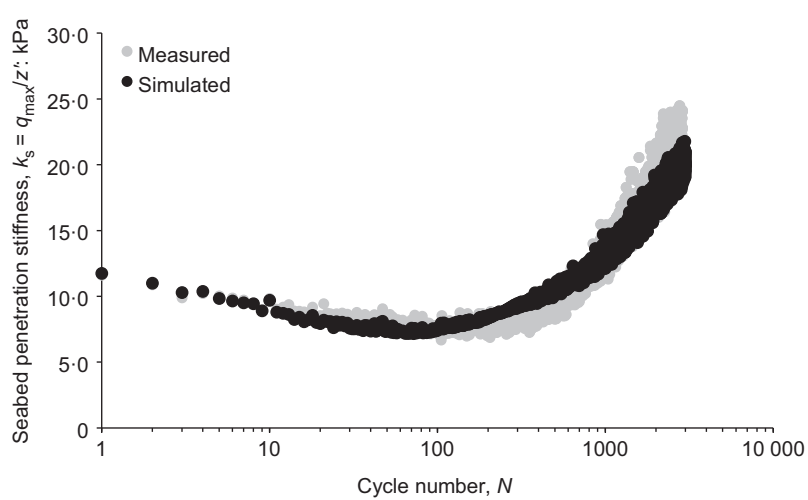

Fig. 11. Comparison of experimental and predicted seabed penetration stiffness during long-term cyclic penetration

Figure 11 compares the simulated and measured evolution of penetration stiffness with cycle number. Both the experimental and simulated results include some scatter as the

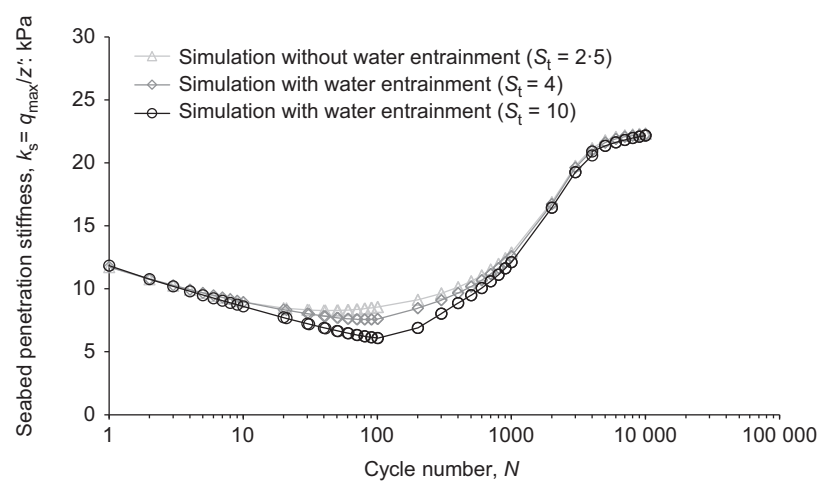

Fig. 12. Effect of water entrainment on seabed penetration stiffness (penetration with a constant applied pressure $q_{p}=8 \mathrm{kPa}$ for each cycle)

limiting pressure achieved in the experiments varied slightly between cycles, in the range from $q_{\mathrm{p}}=8$ to $10 \mathrm{kPa}$. The simulations in Fig. 12 used same limiting value of $q_{\mathrm{p}}$ for each 
Table 3. Summary of framework parameters for simulation cases

\begin{tabular}{|c|c|c|c|c|}
\hline $\begin{array}{l}\text { Framework } \\
\text { component }\end{array}$ & Parameter & Description & Value & Notes on selection or source of selected value \\
\hline Geometry & $D$ & $\begin{array}{l}\text { Diameter of SCR } \\
\quad \text { (prototype scale) }\end{array}$ & $0.5 \mathrm{~m}$ & Typical SCR diameter \\
\hline \multirow[t]{3}{*}{ Soil characteristics } & $\gamma^{\prime}$ & Effective unit weight & $5 \cdot 5 \mathrm{kN} / \mathrm{m}^{3}$ & Young et al. (2000) \\
\hline & OCR & Over-consolidation ratio & & \\
\hline & & Sensitivity & $3 \cdot 5$ & \\
\hline \multirow[t]{4}{*}{ Critical state mode } & $\lambda$ & Compression index & $0 \cdot 205$ & $\begin{array}{l}\text { CRSC tests on Gulf of Mexico clay (Long et al., } \\
\text { 2011) }\end{array}$ \\
\hline & & Swelling index & $0 \cdot 034$ & Assuming $\lambda / \kappa=6$ \\
\hline & $\left(s_{\mathrm{u}} / \sigma_{\mathrm{v} 0}^{\prime}\right)_{\mathrm{NC}}$ & $\begin{array}{l}\text { Normally consolidated } \\
\text { undrained strength ratio }\end{array}$ & $0 \cdot 36$ & $\begin{array}{l}\text { Based on an undrained shear strength gradient } \\
\text { with depth of } 2 \mathrm{kPa} / \mathrm{m} \text { and } \gamma^{\prime}=5.5 \mathrm{kN} / \mathrm{m}^{3}\end{array}$ \\
\hline & $\Gamma_{\mathrm{NCL}}$ & $\begin{array}{l}\text { Specific volume, } v \text {, at } \\
\sigma_{\mathrm{v}}^{\prime}=1 \mathrm{kPa} \text { on } \mathrm{NCL}\end{array}$ & $1 \cdot 9$ & Long et al. (2011) \\
\hline \multirow[t]{3}{*}{$\begin{array}{l}\text { Excess pore pressure } \\
\text { generation }\end{array}$} & $\varepsilon_{99}$ & $\begin{array}{l}\text { Cumulative shear strain } \\
\text { parameter }\end{array}$ & 100 & $\begin{array}{l}\varepsilon_{99} \text { and } p \text { for excess pore pressure generation } \\
\text { determined by specifying an initial strength }\end{array}$ \\
\hline & $p$ & Shear strain rate parameter & $2 \cdot 3$ & gradient of $k=2 \mathrm{kPa} / \mathrm{m}$ \\
\hline & $\beta$ & Strain influence zone extent & $0 \cdot 5 D$ & See section 'Selection of framework parameters' \\
\hline \multirow[t]{2}{*}{ Consolidation process } & $T_{50}$ & $\begin{array}{l}\text { Non-dimensional time for } \\
50 \% \text { consolidation }\end{array}$ & $0 \cdot 09$ & See section 'Selection of framework parameters' \\
\hline & & Embedment level parameter & $1 \cdot 4$ & \\
\hline \multirow{4}{*}{$\begin{array}{l}\text { General soil strength } \\
\text { and stiffness } \\
\text { response }\end{array}$} & $\Phi_{\text {steady }}$ & $\begin{array}{l}\text { Strength parameter at steady, } \\
\text { remoulded conditions }\end{array}$ & $1 \cdot 08$ & $\begin{array}{l}\text { Assume a ratio of drained to undrained soil } \\
\text { strength }=3\end{array}$ \\
\hline & & Strength influence zone extent & $0 \cdot 5 D$ & See section 'Selection of framework parameters' \\
\hline & $K_{\max }$ & Maximum tangent stiffness & 400 & $\begin{array}{l}\text { Taken as upper bound on } K_{\max }=200-400 \text { in } \\
\text { Clukey et al. }(2005,2008) \text { and Randolph \& } \\
\text { Quiggin }(2009) \text {, as the simulations adopt small } \\
\text { displacement cycles }\end{array}$ \\
\hline & $\zeta$ & $\begin{array}{l}\text { Power law parameter for } \\
\text { strength mobilisation }\end{array}$ & $0 \cdot 32$ & See section 'Selection of framework parameters' \\
\hline
\end{tabular}

Table 4. Summary of simulation cases

\begin{tabular}{|c|c|c|c|c|c|c|c|}
\hline \multirow{2}{*}{$\begin{array}{l}\text { Simulation } \\
\text { case no. }\end{array}$} & \multirow{2}{*}{$\begin{array}{l}\text { Coefficient of } \\
\text { consolidation, } \\
c_{\mathrm{v}}: \mathrm{m}^{2} / \text { year }\end{array}$} & \multirow{2}{*}{$\begin{array}{c}\text { Penetration } \\
\text { Applied } \\
\text { pressure, } \\
q_{\mathrm{p}}: \mathrm{kPa}\end{array}$} & \multicolumn{2}{|r|}{ Extraction } & \multirow{2}{*}{$\begin{array}{c}\text { Number of } \\
\text { cycles, } N\end{array}$} & \multirow{2}{*}{$\begin{array}{l}\text { Duration, } t \\
\text { (months/years) }\end{array}$} & \multirow{2}{*}{$\begin{array}{l}\text { Symbol } \\
\text { in Fig. } 16\end{array}$} \\
\hline & & & $\begin{array}{c}\text { Applied } \\
\text { pressure, } \\
q_{\mathrm{p}}: \mathrm{kPa}\end{array}$ & $\begin{array}{c}\text { Normalised } \\
\text { cyclic displacement, } \\
\Delta z / D\end{array}$ & & & \\
\hline 1 & 1 & 4 & - & $0 \cdot 0025$ & $2 \times 10^{8}$ & 60 years & \\
\hline 2 & & & - & 0.025 & $2 \times 10^{8}$ & 60 years & \\
\hline 3 & & & - & $0 \cdot 25$ & $3 \times 10^{7}$ & 10 years & \\
\hline 4 & & & 1 & - & $1.5 \times 10^{8}$ & 45 years & \\
\hline 5 & 10 & & - & $0 \cdot 0025$ & $2 \times 10^{7}$ & $6 \cdot 3$ years & \\
\hline 6 & & & - & 0.025 & $2 \times 10^{7}$ & $6 \cdot 3$ years & \\
\hline 7 & & & - & $0 \cdot 25$ & $1 \times 10^{7}$ & $3 \cdot 15$ years & \\
\hline 8 & & & 1 & - & $2 \times 10^{7}$ & $6 \cdot 3$ years & \\
\hline 9 & 100 & & - & $0 \cdot 0025$ & $9 \times 10^{5}$ & 3.5 months & -- \\
\hline 10 & & & - & 0.025 & $8 \times 10^{5}$ & 3 months & \\
\hline 11 & & & - & $0 \cdot 25$ & $6 \times 10^{5}$ & $2 \cdot 3$ months & \\
\hline 12 & & & 1 & - & $8 \times 10^{5}$ & 3 months & \\
\hline
\end{tabular}

cycle as in the experiments. The initial reduction in stiffness over the first $\sim 100$ cycles reflects the lower soil strength due to remoulding. This stiffness is regained as the soil strength increases through consolidation, with final values of $k_{\mathrm{s}}$ that are approximately 1.8 times the initial value. This trend is captured well by the simulations.

To illustrate the sensitivity of the response to the extent that the soil softens due to water entrainment, additional simulations were conducted using different values of $S_{\mathrm{t}}=2 \cdot 5$, 4 and 10 with a constant applied pressure, $q_{\mathrm{p}}=8 \mathrm{kPa}$, for 10000 cycles. The results are summarised in Fig. 12, and show that, although $S_{\mathrm{t}}$ affects $k_{\mathrm{s}}$ in the short term (over the first 200 cycles) by calculating a lower soil strength, the long-term response results in limiting values of $k_{\mathrm{s}}$ that are independent of $S_{\mathrm{t}}$. This is a useful finding as it emphasises that the long-term stiffness - most relevant to fatigue - is independent of the water entrainment, so that quantifying this effect is a low priority.

\section{FIELD-SCALE EXAMPLE ANALYSES}

The simulations described above show that the effective stress framework can capture the influence of both remoulding and consolidation, to replicate the changes in strength 


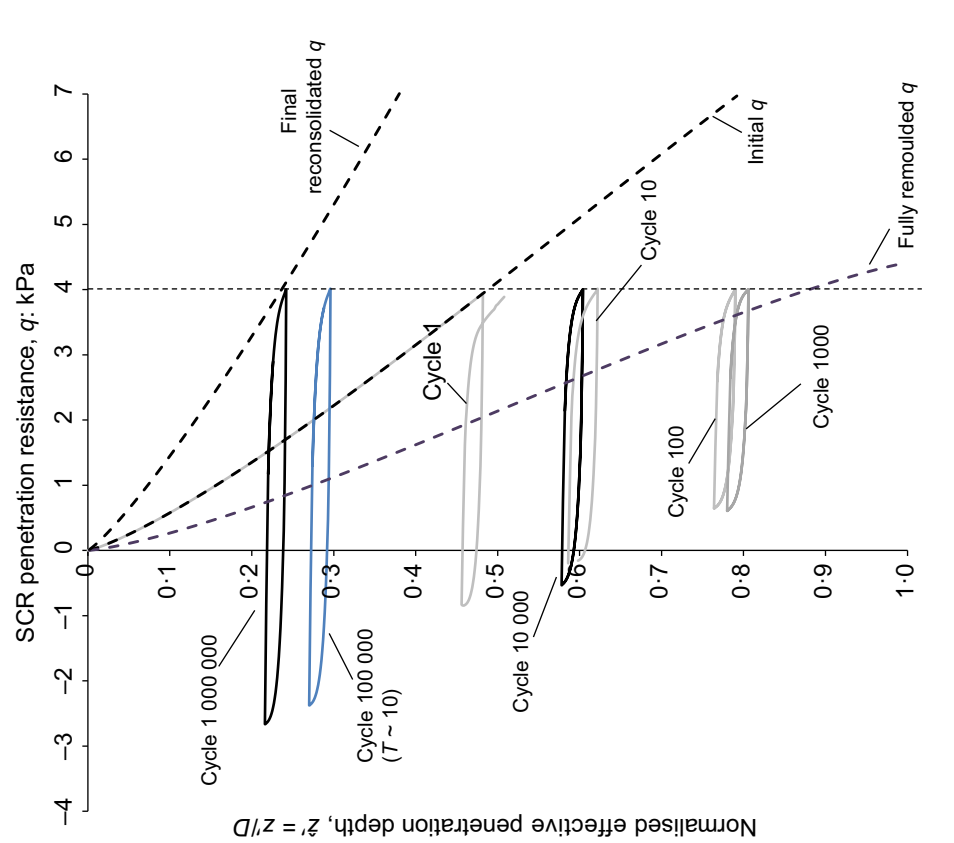

竞
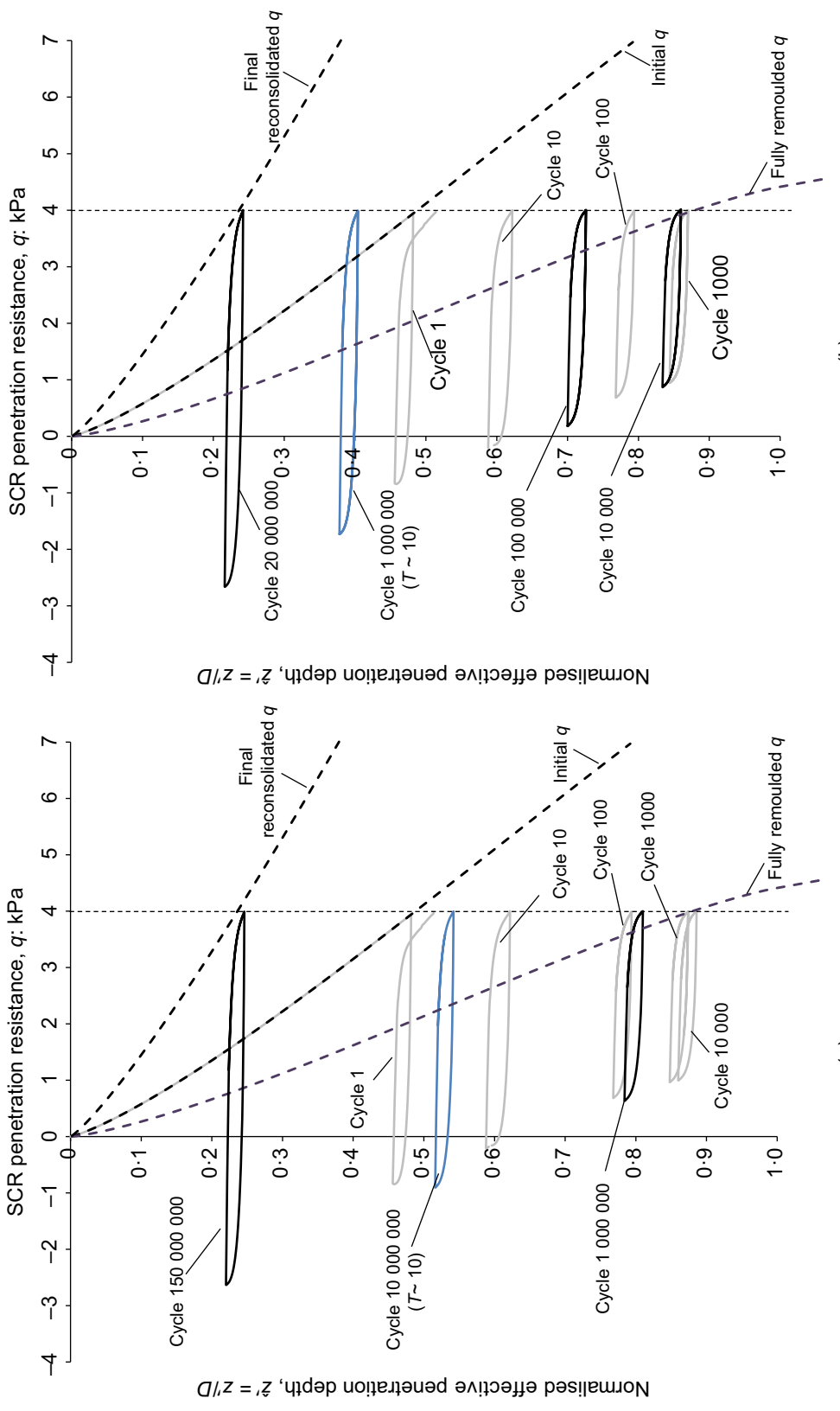


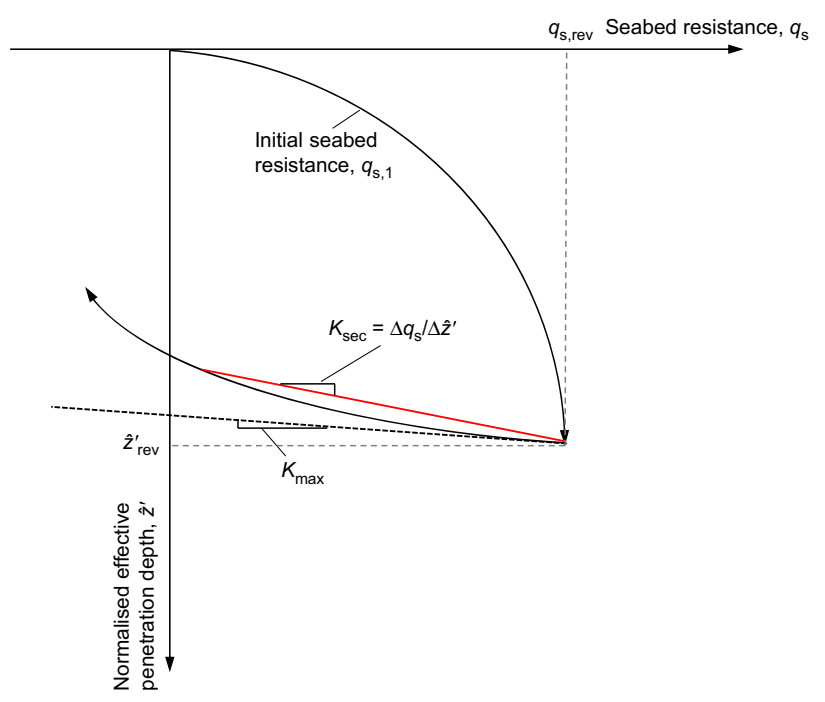

Fig. 14. Definition of unloading secant stiffness, $K_{\text {sec }}$

and stiffness that occur during centrifuge tests that involve both effects. The framework is therefore a useful tool to evaluate the relative influence of remoulding and consolidation on the long-term SCR-seabed stiffness, which has a significant influence on fatigue life, as explored in this closing section.

A particular benefit of the framework is that it allows the response to be scaled from the centrifuge tests conditions to field conditions, where the relative rates of cycling and consolidation are very different. In centrifuge tests, apparatus limitations prevent the motion cycles from being performed at a frequency that matches the rate at which pore pressure dissipation is accelerated - which is $N^{2}$, where $N$ is the centrifuge acceleration. In the centrifuge tests of Yuan et al. (2017), $N=50$, so dissipation processes were accelerated by 2500 times relative to field conditions. However, the motion cycles had a period of approximately $1 \mathrm{~s}$ in the long-term test, relative to a field oscillation frequency that would be in the order of $10 \mathrm{~s}$, so were accelerated only by a factor of 10 . An alternative way to express this is that, in the field, 250 times more cycles would occur in the same period of pore pressure dissipation that was modelled in the centrifuge tests. This scaling mismatch means that the relative contributions of remoulding and consolidation may not be correct, and an unrealistically high level of consolidation is associated with a given number of cycles in the centrifuge.

This limitation of the centrifuge modelling is overcome using the framework, which allows the effects of remoulding and consolidation on long-term seabed stiffness to be evaluated, with the confidence that the model parameters are calibrated to the centrifuge tests. A set of 12 simulations were conducted using the parameters given in Table 3 . These parameters were chosen to represent normally consolidated soft clay in the Gulf of Mexico, where SCRs are widely used. The simulations adopted an SCR diameter, $D=0.5 \mathrm{~m}$ and an applied pressure, $q_{\mathrm{p}}=4 \mathrm{kPa}$, considered representative for soft seabeds (Shiri, 2010). Summarised in Table 4, the 12 simulations are arranged into three groups, all with a penetration 'limit' of $q_{\mathrm{p}}=4 \mathrm{kPa}$, but with the same four variations on extraction limits for each cycle. These were extraction to $q_{\mathrm{p}}=1 \mathrm{kPa}$, and extraction by displacements of $0.0025 D, 0.025 D$ and $0 \cdot 25 D$. Each group considered two orders of magnitude variation in the coefficient of consolidation, $\left(c_{\mathrm{v}}=1,10\right.$ and $100 \mathrm{~m}^{2} /$ year $)$ to explore the timescales over which the SCR stiffness changes.

In practice, at a given location in an SCR touchdown zone, the penetration stress limit may reduce with cycles as a trench forms and the concentrated vertical load spreads along the touchdown zone. This may reduce the trenching and stiffening effect seen at that point, but will raise the effect seen at adjacent points.

Example results from the simulations are provided in Fig. 13, which shows the variation in SCR penetration resistance against normalised effective penetration depth for cases 2,6 and $10\left(c_{\mathrm{v}}=1,10\right.$ and $100 \mathrm{~m}^{2} /$ year, respectively, and an uplift displacement of $0 \cdot 025 D$ ). Consistent with the observations from the centrifuge tests of Yuan et al. (2017), the cyclic hysteresis loop becomes deeper over the first $N=1000$ cycles as the soil progressively remoulds, but then becomes shallower due to consolidation-induced increases in soil strength, and a higher $c_{\mathrm{v}}$ results in a quicker regain in soil strength and SCR penetration resistance.

Figure 15 shows the variation in SCR-seabed stiffness with cycle number for the $c_{\mathrm{v}}=10 \mathrm{~m}^{2} /$ year simulations. The stiffness adopted is an unloading secant stiffness, $K_{\text {sec }}$, defined in Fig. 14 as

$$
K_{\mathrm{sec}}=\Delta q_{s} / \Delta z=\left(q_{\mathrm{s}}-q_{\mathrm{s}, \mathrm{rev}}\right) /\left(\hat{z}-\hat{z}_{\mathrm{rev}}\right)
$$

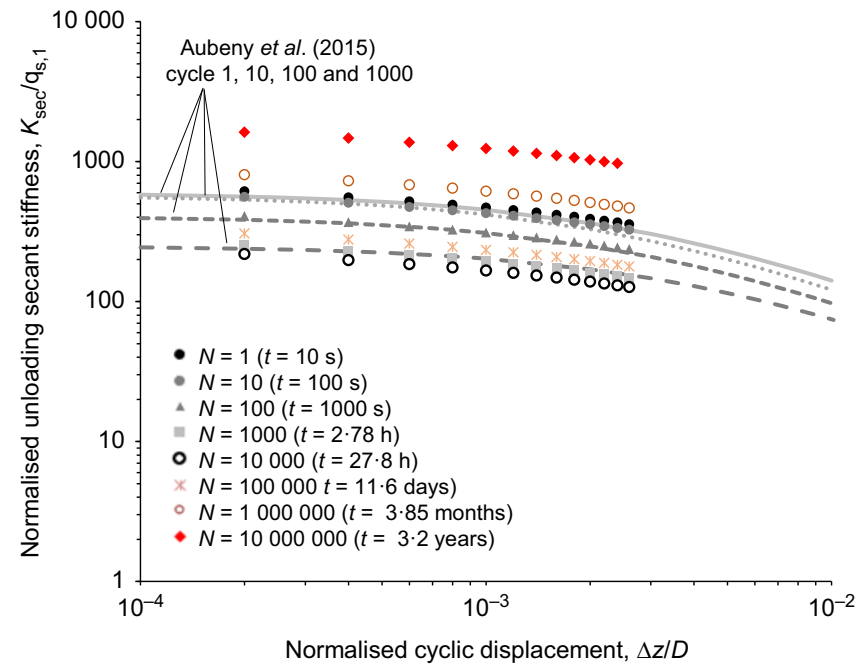

(a)

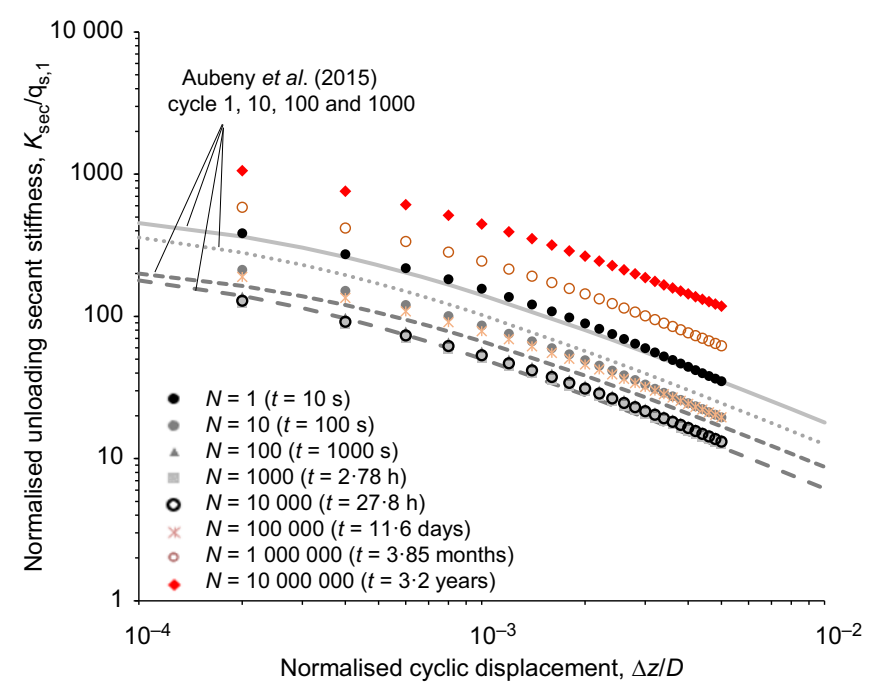

(b)

Fig. 15. Variation in unloading secant stiffness: (a) case 5; (b) case 7 


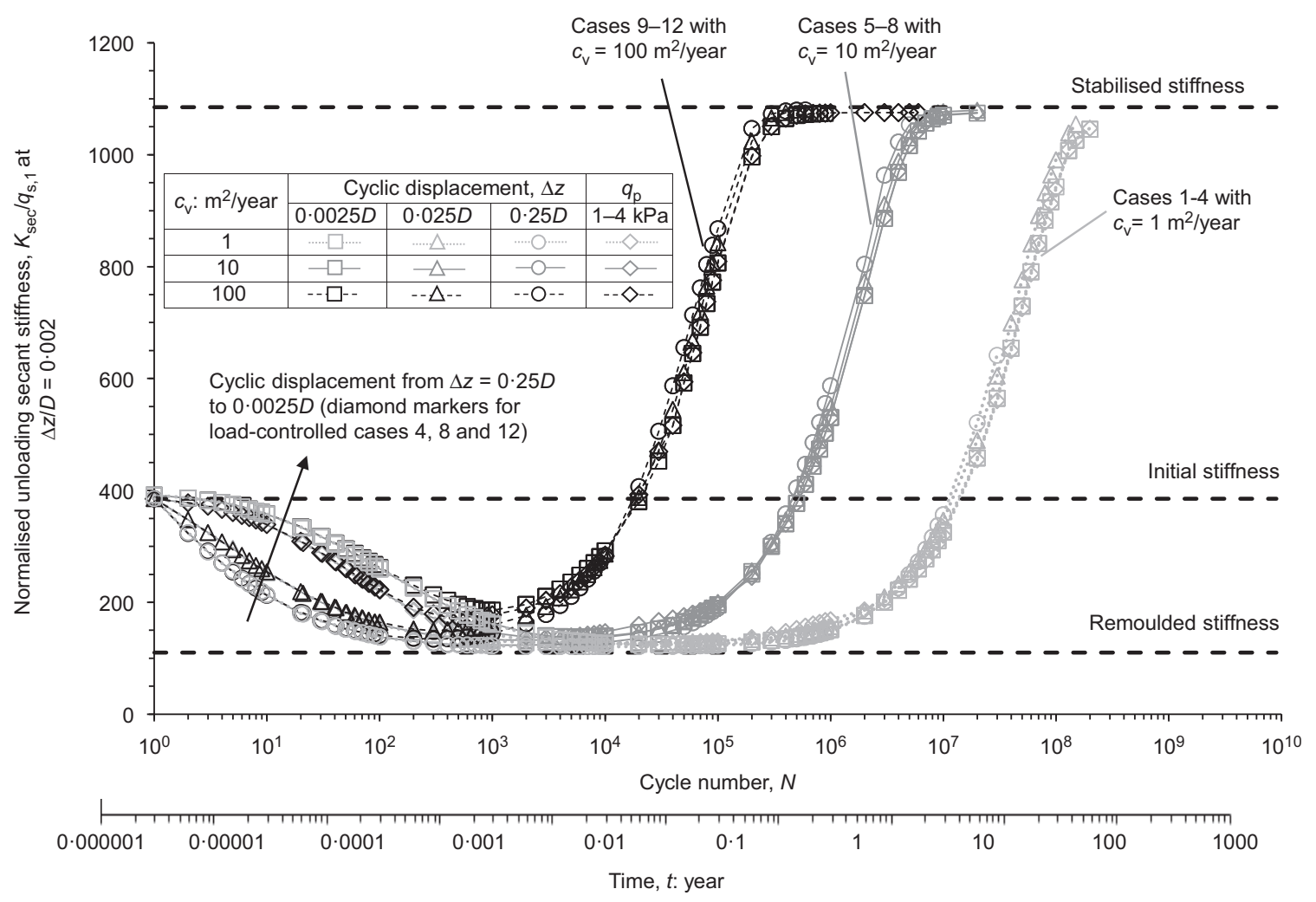

(a)

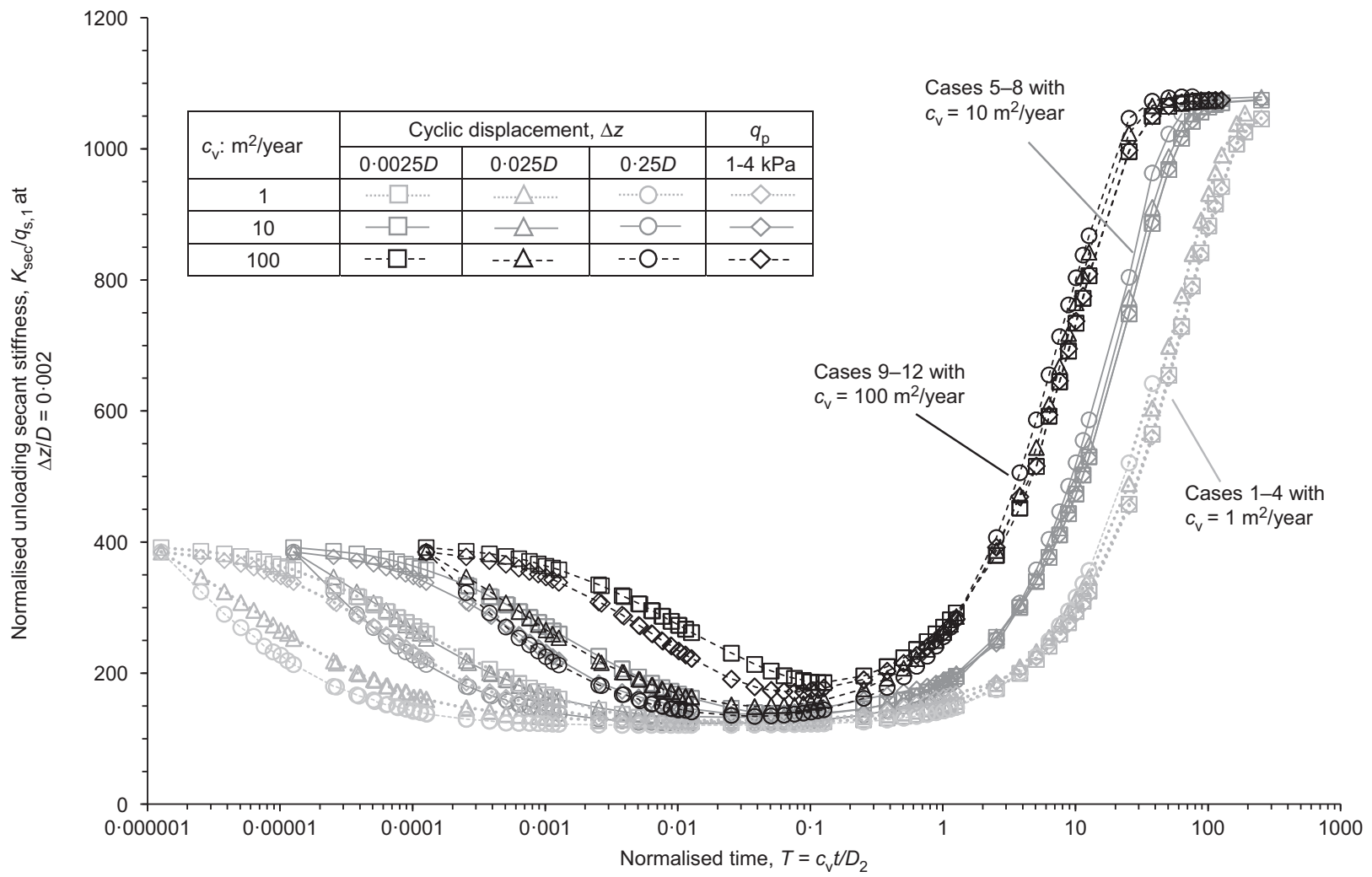

Fig. 16. Evolution of normalised unloading secant stiffness, $K_{\mathrm{sec}} l q_{\mathrm{s}, 1}$, at $\Delta z I D=0 \cdot 002$ : (a) shown against cycle number, $N$, and time, $t$; (b) shown against normalised time, $T$

where $q_{\mathrm{s} \text { rev }}$ and $\hat{z}_{\text {rev }}$ are the seabed resistance and normalised penetration depth corresponding to the last point of load reversal. Fig. 15 shows the expected reduction in $K_{\mathrm{sec}}$ with normalised cyclic displacement, $\Delta z / D$, and also the trend of reducing and then increasing $K_{\mathrm{sec}}$ with cycle number, associated with initial softening and then consolidationinduced hardening of the soil. The degradation of secant stiffness can also be captured by existing SCR-seabed stiffness models, as demonstrated in Fig. 15 by the Aubeny et al. (2015) model using parameters that lead to the same amount of 
softening behaviour over the same loading period as the current model. However, the existing models do not predict the regain in the stiffness due to consolidation, so they predict a long-term stiffness that is much lower than the eventual value.

Figure 16 presents the evolution of secant stiffness at a cyclic displacement of $\Delta z / D=0 \cdot 002$. The results are shown against cycle number, $N$, and time, $t$, in Fig. 16(a) and against dimensionless time, T, in Fig. 16(b). As indicated by Fig. 15, the simulations capture both the initial reduction and subsequent increase in stiffness. The rate of stiffness reduction is controlled by the cyclic displacement adopted for each cycle, such that at low cycle numbers the simulations group according to the cyclic displacement and are independent of $c_{\mathrm{v}}$.

In contrast, the increase in stiffness is controlled by the consolidation duration, such that at larger cycle numbers the simulations group according to $c_{\mathrm{v}}$. Stiffness eventually stabilises at cycle numbers and durations that depend on $c_{\mathrm{v}}$; the $c_{\mathrm{v}}=100 \mathrm{~m}^{2} /$ year cases stabilise after 1.5 months $\left(N=3 \cdot 5 \times 10^{5}\right)$, the $c_{\mathrm{v}}=10 \mathrm{~m}^{2} /$ year cases stabilise after $3 \cdot 2$ years $\left(N=1 \times 10^{7}\right)$ and the $c_{\mathrm{v}}=1 \mathrm{~m}^{2} /$ year cases stabilise after 60 years $\left(N=2 \times 10^{8}\right)$. Hence, for a typical design life of 30 years, the SCR-seabed stiffness for the majority of the life is the long-term steady-state fully reconsolidated stiffness, except for a seabed with $c_{\mathrm{v}}=1 \mathrm{~m}^{2} /$ year, for which the SCR-seabed stiffness is $55 \%, 75 \%$ and $90 \%$ of the stabilised (and maximum) $K_{\mathrm{sec}}$ after 10, 20 and 30 years, respectively.

The use of dimensionless time, $T$, in Fig. 16(b) tends to eliminate the influence of $c_{\mathrm{v}}$, although some dependence remains during the early stages as the higher $c_{\mathrm{v}}$ cases reach a state in which cycles do not generate any pore pressure more quickly, and during the consolidation stage the deviation of $K_{\mathrm{sec}} / q_{\mathrm{s}, \mathrm{i}}$ between the three $c_{\mathrm{v}}$ groups is affected by the SCR embedment depth. This is because the soil horizons at different depths experienced different remoulding at the same $T$, which results in a different ratio between $q_{\mathrm{s}} / q_{\mathrm{s}, \mathrm{i}}$. For example, in Fig. 13, the cycles at $T \sim 10$ are highlighted for the cases with different values of $c_{\mathrm{v}}$, showing the difference in embedded depth and therefore $q_{\mathrm{s}, \mathrm{i}}$ at the same dimensionless time. However, all the simulations approach the same stabilised depth and stiffness, and this gain in stiffness was $50 \%$ complete at a dimensionless time of $T \sim 10$ on average. For these example cases, this stiffness is about 3 times higher than the initial stiffness and $\sim 10$ times higher than would be predicted as the steady-state remoulded value assumed in current SCR-seabed stiffness models.

\section{CONCLUSIONS}

Compared with current published models and design practice, in which SCR-seabed interaction is analysed using a total stress approach ignoring any influence of the dissipation of excess pore water pressure, the analysis proposed in this paper shows a significant improvement. Three important contributions are made.

1. The new method uses an effective stress framework, and is defined with sufficient generality to allow realistic simulation of 'whole-life' cyclic loading histories. This unlocks the 'hidden' effect of consolidation on soil strength and stiffness, rather than using a predefined empirical factor applied to the intact soil strength and resistance, as is current practice.

2. A sound theory is proposed that captures the experimental observations, allowing reliable prediction of changes in penetration resistance and stiffness through remoulding and reconsolidation - including extrapolation from centrifuge tests to arbitrary field conditions.
3. Many of the model parameters are derived from full-flow penetrometer test data, such that there is the potential to bridge between in situ tests and SCR design predictions.

A series of simulations is presented to illustrate a range of typical field scenarios, and show the progressive rise in stiffness during continuous cycling motion, due to consolidation. It is shown that current design practice may underestimate the seabed stiffness significantly, but the new approach allows rapid checking of this for particular combinations of SCR and soil conditions.

\section{ACKNOWLEDGEMENTS}

The first author acknowledges his research studentship support from the ARC Industrial Transformation Research Hub for Offshore Floating Facilities and the University of Western Australia. This work was supported by the ARC Industrial Transformation Research Hub for Offshore Floating Facilities, which is funded by the Australia Research Council, Woodside Energy, Shell, Bureau Veritas and Lloyds Register (grant no. IH140100012).

\section{NOTATION}

$b \quad$ peak strength parameter, $k_{\Phi}(\hat{z})=\operatorname{OCR}(\hat{z})^{b}$

$c_{\mathrm{v}}$ coefficient of consolidation

$D$ diameter of steel catenary riser (SCR)

$K$ tangent stiffness

$K_{\max }$ maximum tangent stiffness adopted since the last reversal in penetration or extraction

$k_{\Phi} \quad$ strength parameter multiplier

$m$ parameter for dissipation rate

$N_{\mathrm{c}} \quad$ bearing capacity factor

$p$ parameter for pore pressure generation rate

$q$ SCR penetration resistance

$q_{\mathrm{p}}$ applied pressure

$q_{\mathrm{s}}$ seabed resistance

$S_{\mathrm{t}} \quad$ soil sensitivity

$s_{\mathrm{u}} \quad$ undrained shear strength

$s_{\mathrm{u}}(\bar{z}) \quad$ undrained shear strength profile

$s_{\mathrm{u}, \mathrm{av}}$ average undrained shear strength

$s_{\mathrm{u}, \mathrm{mob}}$ mobilised soil strength

$\left(s_{\mathrm{u}} / \sigma_{\mathrm{v} 0}^{\prime}\right)_{\mathrm{NC}}$ normally consolidated undrained strength ratio

$T$ dimensionless time factor

$T_{50}$ dimensionless time factor required for $50 \%$ dissipation of the initial excess pore pressure

$t$ reconsolidation period

$u_{\mathrm{e}}(\bar{z}) \quad$ excess pore pressure profile

$u_{\mathrm{e}, \max }(\bar{z})$ maximum excess pore pressure profile

$u_{\mathrm{e}, \mathrm{r}}(\bar{z})$ remaining potential excess pore pressure profile

$v$ specific volume

$v_{\text {initial }}$ initial specific volume

$v_{\mathrm{s}}(\hat{z}) \quad$ strength influence function

$z$ soil depth

$\hat{z}$ normalised soil depth, $z / D$

$z_{\mathrm{e}} \quad$ depth of reference point of SCR below soil surface

$\hat{z}_{\mathrm{e}} \quad$ normalised depth, $z_{\mathrm{e}} / D$

$\alpha$ extent of strength influence zone

$\beta$ extent of strain influence zone

$\Gamma_{\mathrm{NCL}}$ specific volume, $v, \sigma_{\mathrm{v}}^{\prime}=1 \mathrm{kPa}$ on the normal consolidation line (NCL)

$\gamma^{\prime}$ soil effective unit weight

$\varepsilon \quad$ cumulative (absolute) shear strain

$\varepsilon_{95, \Phi} \quad$ peak strength ductility parameter

$\varepsilon_{99}$ cumulative (absolute) shear strain required for a degree of remoulding equal to $99 \%$

$\zeta$ non-linear tangent stiffness parameter

$\eta$ load-sharing factor

$\kappa$ swelling index

$\Lambda$ plastic volumetric strain ratio

$\lambda$ compression index

$\mu(\hat{z}) \quad$ strain influence distribution function 


$\begin{aligned} \sigma_{\mathrm{v}}^{\prime} & \text { vertical effective stress } \\ \sigma_{\mathrm{v} 0}^{\prime} & \text { in situ geostatic effective stress } \\ \sigma_{\mathrm{v}, \text { eqm }}^{\prime} & \text { equilibrium vertical effective stress } \\ \sigma_{\mathrm{v}, \mathrm{NCL}}^{\prime} & \text { vertical effective stress at NCL } \\ \sigma_{\mathrm{v}, \mathrm{RSL}}^{\prime} & \text { vertical effective stress at RSL } \\ \Phi & \text { lumped strength parameter } \\ \Phi_{\text {steady }} & \text { steady value of lumped strength parameter } \\ \chi & \text { characteristic pressure } \\ \Psi & \text { vertical distance between the object penetration depth } \\ & \text { and a given soil horizon normalised by the object } \\ & \text { diameter }\end{aligned}$

\section{REFERENCES}

Aubeny, C. \& Biscontin, G. (2009). Seafloor-riser interaction model. Int. J. Geomech. 9, No. 3, 133-144.

Aubeny, C., White, T., Langford, T., Meyer, V. \& Clukey, E. (2015). Seabed stiffness model for steel catenary risers. In Frontiers in offshore geotechnics III (ed. V. Meyer), pp. 351-356. Boca Raton, FL, USA: CRC Press.

Bridge, C., Laver, K., Clukey, E. \& Evans, T. (2004). Steel catenary riser touchdown point vertical interaction models. Proceedings of the offshore technology conference, Houston, TX, USA, paper no. OTC 16628

Chatterjee, S., White, D. J. \& Randolph, M. F. (2013). Coupled consolidation analysis of pipe-soil interactions. Can. Geotech. J. 50, No. 6, 609-619.

Clukey, E. C. \& Zakeri, A. (2017). Recent advances in nonlinear soil models for fatigure evaluation of steel catenary risers SCRs. Proceedings of the offshore technology conference, Houston, TX, USA, paper no. OTC 27627.

Clukey, E. C., Haustermans, L. \& Dyvik, R. (2005). Model tests to simulate riser-soil interaction in touchdown point region. In Frontiers in offshore geotechnics (eds S. Gourvenec and M. Cassidy), pp. 651-658. Boca Raton, FL, USA: CRC Press/ Balkema.

Clukey, E. C., Young, A. G., Dobias, J. R. \& Garmon, G. R. (2008). Soil response and stiffness laboratory measurements of SCR pipe/soil interaction. Proceedings of the offshore technology conference, Houston, TX, USA, paper no. OTC 19303.

Clukey, E. C., Aubeny, C. P., Randolph, M. F., Sharma, P. P., White, D. J., Sancio, R. \& Cerkovnik, M. (2017). A Perspective on the state of knowledge regarding soil-pipe interaction for SCR fatigue assessments. Proceedings of the offshore technology conference, Houston, TX, USA, paper no. OTC 27564.

Colreavy, C., O'Loughlin, C. D. \& Randolph, M. F. (2016). Experience with a dual pore pressure element piezoball. Int. J. Phys. Modelling Geotech. 16, No. 3, 101-118.

Einav, I. \& Randolph, M. F. (2005). Combining upper bound and strain path methods for evaluating penetration resistance. Int. J. Numer. Methods Engng 63, No. 14, 1991-2016.

Elosta, H., Huang, S. \& Incecik, A. (2013). Dynamic response of steel catenary riser using a seabed interaction under random loads. Ocean Engng 69, 34- 43.

Elosta, H., Huang, S. \& Incecik, A. (2014). Trenching effects on structural safety assessment of integrated riser/semisubmersible in cohesive soil. Engng Structs 77, 57-64.

Feng, X. \& Gourvenec, S. (2016). Modelling sliding resistance of tolerably mobile subsea mudmats. Géotechnique 66, No. 6, 490-499, https://doi.org/10.1680/jgeot.15.P.178.

Gaudin, C. \& White, D. J. (2009). New centrifuge modelling techniques for investigating seabed pipeline behaviour. In Proceedings of the 17th international conference on soil mechanics and geotechnical engineering (eds M. Hamza, M. Shahien and Y. El-Mossallamy), vol. 1, pp. 448-451. Amsterdam, the Netherlands: IOS Press.

Gaudin, C., O’Loughlin, C. D., Hossain, M. S., Randolph, M. F. \& Colliat, J. L. (2014). Installation of suction caissons in Gulf of Guinea clay. In ICPMG2014 - physical modelling in geotechnics (eds C. Gaudin and D. White), pp. 493-499. Boca Raton, FL, USA: CRC Press.

Gourvenec, S. M. \& White, D. J. (2010). Elastic solutions for consolidation around seabed pipelines. Proceedings of the offshore technology conference, Houston, TX, USA, paper no. OTC 20554.
Guha, I., Randolph, M. F. \& White, D. J. (2016). Evaluation of elastic stiffness parameters for pipeline-soil interaction. J. Geotech. Geoenviron. Engng 142, No. 6, https://doi.org/ 10.1061/(ASCE)GT.1943-5606.0001466.

Hodder, M. White, D. J. \& Cassidy, M. J. (2009). Effect of remolding and reconsolidation on the touchdown stiffness of a steel catenary riser: Observations from centrifuge modelling. Proceedings of the offshore technology conference, Houston, TX, USA, paper no. OTC 19871.

Hodder, M. S., White, D. J. \& Cassidy, M. J. (2013). An effective stress framework for the variation in penetration resistance due to episodes of remoulding and reconsolidation. Géotechnique $\mathbf{6 3}$, No. 1, 30-43, https://doi.org/10.1680/geot.9.P.145.

Hou, Z., Sahdi, F., Gaudi, C. \& Randolph, M. F. (2018). Evolution of riser-soil stiffness in a soil crust layer. In Proceedings of the 1 st Vietnam symposium on advances in offshore engineering. energy and geotechnics (eds M. F. Randolph, D. H. Doan, A. M. Tang, M. Bui and V. N. Dinh), pp. 130-136. Singapore: Springer Nature Singapore.

House, A., Olivera, J. R. M. S. \& Randolph, M. F. (2001). Evaluating the coefficient of consolidation using penetration tests. Int. J. Phys. Modelling Geotech. 1, No. 3, 17-26.

Kimiaei, M., Randolph, M. F. \& Ting, I. (2010). A parametric study on effects of environmental loadings on fatigue life of steel catenary risers (using a nonlinear cyclic riser-soil interaction model). Proceedings of the 29th international conference on ocean, offshore and arctic engineering, Shanghai, China, paper no. OMAE2010-21153.

Li, F. Z. \& Low, Y. M. (2012). Fatigue reliability analysis of a steel catenary riser at the touchdown point incorporating soil model uncertainties. Appl. Ocean Res. 38, 100-110.

Long, H., Flemings, P. B., Germaine, J. T. \& Saffer, D. M. (2011). Consolidation and overpressure near the seafloor in the Ursa Basin, Deepwater Gulf of Mexico. Earth Planetary Sci. Lett. 305, No. 1-2, 11-20.

Martin, C. M. \& Randolph, M. (2006). Upper-bound analysis of lateral pile capacity in cohesive soil. Géotechnique 56, No. 2, 141-145, https://doi.org/10.1680/geot.2006.56.2.141.

Merifield, R. S., White, D. J. \& Randolph, M. F. (2009). Effect of surface heave on the response of partially embedded pipelines on clay. J. Geotech. Geoenviron. Engng 135, No. 6, https://doi.org/ 10.1061/(ASCE)GT.1943-5606.0000070.

O’Beirne, C., O’Loughlin, C. D. \& Gaudin, C. (2017). Assessing the penetration resistance acting on a dynamically installed anchor in normally consolidated and overconsolidated clay. Can. Geotech. J. 54, No. 1, 1-17.

Queau, L. M., Kimiaei, M. \& Randolph, M. F. (2013). Dimensionless groups governing response of steel catenary risers. Ocean Engng 74, 247-259.

Randolph, M. F. \& Quiggin, P. (2009). Non-linear hysteretic seabed model for catenary pipeline contact. Proceedings of the 28th international conference on ocean, offshore and arctic engineering, Honolulu, HI, USA, paper no. OMAE2009-79259.

Randolph, M. F. \& White, D. J. (2008a). Pipeline embedment in deep water: processes and quantitative assessment. Proceedings of the offshore technology conference, Houston, TX, USA, paper no. OTC 19128.

Randolph, M. F. \& White, D. J. (2008b). Upper-bound yield envelopes for pipelines at shallow embedment in clay. Géotechnique 58, No. 4, 297-301, https://doi.org/10.1680/geot. 2008.58.4.297.

Richardson, M. D., O’Loughlin, C. D., Randolph, M. F. \& Gaudin, C. (2009). Setup following installation of dynamic anchors in normally consolidated clay. J. Geotech. Geoenviron. Engng 135, No. 4, 487-496.

Shiri, H. (2010). Influence of seabed response on fatigue performance of steel catenary risers in touchdown zone. $\mathrm{PhD}$ thesis, The University of Western Australia, Perth, WA, Australia.

Stewart, D. P. (1992). Lateral loading of piled bridge abutments due to embankment construction. $\mathrm{PhD}$ thesis, The University of Western Australia, Perth, WA, Australia.

Tika, T. E. \& Hutchinson, J. N. (1999). Ring shear tests on soil from the Vaiont landslide slip surface. Géotechnique 49, No. 1, 59-74, https://doi.org/10.1680/geot.1999.49.1.59.

Voie, P. E., Skeie, G. \& Bergan-Haavik, J. (2014). Importance rating of riser-soil interaction effects. Proceedings of the 
$33 r d$ international conference on ocean, offshore and arctic engineering, San Francisco, CA, USA, paper no. OMAE2014-24179.

White, D. J. \& Hodder, M. (2010). A simple model for the effect on soil strength of episodes of remoulding and reconsolidation. Can. Geotech. J. 47, No. 7, 821-826.

White, D. J., Gaudin, C., Boylan, N. \& Zhou, H. (2010). Interpretation of T-bar penetrometer tests at shallow embedment and in very soft soils. Can. Geotech. J. 47, No. 2, 218-229.

You, J., Biscontin, G. \& Aubeny, C. P. (2008). Seafloor interaction with steel catenary risers. Proceedings of the 8th international offshore and polar engineering conference, Vancouver, BC, Canada, paper no. ISOPE-I-08-303.

Young, A. G., Honganen, C., Silva, A. \& Bryant, W. (2000). Comparison of geotechnical properties from large diameter long cores and borings in deepwater Gulf of Mexico. Proceedings of the offshore technology conference, Houston, TX, USA, paper no. OTC 12089.

Yuan, F., White, D. J. \& O'Loughlin, C. D. (2017). The evolution of seabed stiffness during cyclic movement in a riser touchdown zone on soft clay. Géotechnique 67, No. 2, 127-137, https://doi.org/10.1680/jgeot.15.P.161.

Zargar, E. (2017). A new hysteretic seabed model for riser-soil interaction. $\mathrm{PhD}$ thesis, The University of Western Australia, Perth, Australia.

Zhou, Z., White, D. J. \& O'Loughlin, C. D. (2019). An effective stress framework for estimating penetration resistance accounting for changes in soil strength from maintained load, remoulding and reconsolidation. Géotechnique 69, No. 1, 57-71, https://doi.org/10.1680/jgeot.17.P.217. 